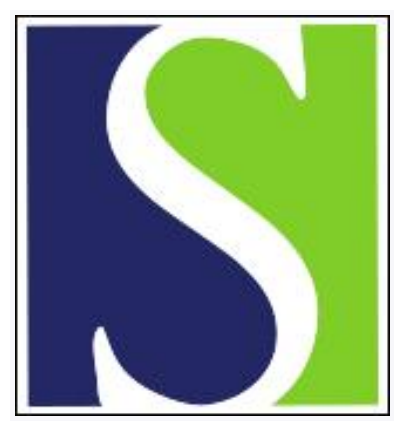

Scand J Work Environ Health 1999;25(3):186-206

https://doi.org/10.5271/sjweh.424

Issue date: Jun 1999

Exposure-response of asphalt fumes with changes in pulmonary function and symptoms

by Gamble JF, Nicolich MJ, Barone NJ, Vincent WJ

Key terms: acute effect; asphalt fumes; benzene-soluble fraction; exposure assessment; heat stress irritation; lung function; nonparametric statistics; shift study; symptom; total particulate; volatile hydrocarbon

This article in PubMed: www.ncbi.nlm.nih.gov/pubmed/10450769

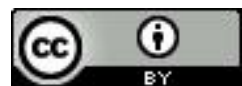




\title{
Exposure-response of asphalt fumes with changes in pulmonary function and symptoms
}

\author{
by John F Gamble, PhD, ${ }^{1}$ Mark J Nicolich, PhD, ${ }^{1}$ Neil J Barone, MPH, ${ }^{1}$ Wesley J Vincent, MSPH ${ }^{1}$
}

Gamble JF, Nicolich MJ, Barone NJ, Vincent WJ. Exposure-response of asphalt fumes with changes in pulmonary function and symptoms. Scand J Work Environ Health 1999;25(3):186-206.

\begin{abstract}
Objectives This study examines possible associations between asphalt fumes and workshift changes in lung function and symptoms among 170 workers exposed to asphalt fumes.

Methods The workers, were from 5 segments of the asphalt industry, and most of them participated for 2 consecutive workdays. The primary response variables were changes in lung function (measured at the beginning and end of the shift) and incidence of symptoms (measured before, 3 times during, and at the end of the shift). Exposure was estimated from breathing-zone samples of total particulate (TP), respirable particulate (RP), the benzene-soluble fraction of the TP (BSF), volatile hydrocarbons collected on a charcoal tube (VHC), nitrogen dioxide, sulfur dioxide, formaldehyde, carbon monoxide, and hydrogen sulfide. Ozone and wet bulb/dry bulb temperature, as a measure of heat stress, were measured as area samples. In addition, daily cigarette smoking was determined by questionnaire. The exposure-response associations were assessed by both parametric and nonparametric statistical techniques.

Results Overall, no consistent association was observed between an acute reduction in lung function or the incidence of symptoms and exposure to asphalt fumes. Concentrations in the neighborhood of the maximum levels constitute no-observed adverse effect levels: TP $\left(<1.5 \mathrm{mg} / \mathrm{m}^{3}\right.$ to maximum $\left.6.2 \mathrm{mg} / \mathrm{m}^{3}\right), R P\left(<0.6 \mathrm{mg} / \mathrm{m}^{3}\right.$ to maximum $\left.1.4 \mathrm{mg} / \mathrm{m}^{3}\right)$, BSF $\left(<0.6 \mathrm{mg} / \mathrm{m}^{3}\right.$ to maximum $\left.1.3 \mathrm{mg} / \mathrm{m}^{3}\right)$, VHC $\left(<8 \mathrm{mg} / \mathrm{m}^{3}\right.$ to maximum $\left.19.8 \mathrm{mg} / \mathrm{m}^{3}\right)$. There were no exposure-response trends with ozone, heat stress, cigarettes smoked, or length of workday.
\end{abstract}

Key terms acute effects, asphalt fumes, benzene-soluble fraction, exposure assessment, heat stress irritation, lung function, nonparametric statistics, shift study, symptoms, total particulate, volatile hydrocarbons.

Asphalt is a complex mixture containing many high-molecular-weight organic compounds made by processing petroleum crude oils. Asphalt composition varies depending on the end use and the source of the crude oil, refinery processes, additives, and application practices. For example, over 100 crude oil sources are used in the United States. In the refining process, paving asphalt is generally made from residuum of the vacuum distillation process, while roofing asphalts are usually air blown. Application temperatures vary and are typically $135-$ $163^{\circ} \mathrm{C}$ for paving asphalt and $232-275^{\circ} \mathrm{C}$ for roofing asphalt. Asphalt is principally used in the United States today for road paving (about $87 \%$ ) and roofing (about $11 \%$ ) (1). The estimated work force in 1981-1983 was about 500000 workers (2).

The current threshold limit value (TLV®) of the American Conference of Governmental Industrial
Hygienists (ACGIH) for asphalt fumes was set at $5 \mathrm{mg} /$ $\mathrm{m}^{3}$ as the 8-hour time-weighted average (TWA) to "maintain good housekeeping conditions and reduce the risk of possible carcinogenicity" (3). ACGIH (4) is proposing a change of the asphalt TLV (B from $5 \mathrm{mg} / \mathrm{m}^{3}$ for total particulate (TP) to $0.5 \mathrm{mg} / \mathrm{m}^{3}$ for the cyclohexane-soluble fraction of inhalable particulate matter (CSF).

The proposed change in the TLV(B) is based on the increased mucous membrane and eye irritation found in several studies. For example, Hervin \& Emmett $(5,6)$ reported an increased occurrence of conjunctivitis among roofers exposed to asphalt and coal tar at concentrations greater than $0.2 \mathrm{mg} / \mathrm{m}^{3}$ for the cyclohexane-soluble fraction of total particulate. Both the authors and the workers attributed the conjunctivitis to exposure to coal tar. Norseth et al (7) reported increased symptoms at average weekly concentrations of $0.4 \mathrm{mg} / \mathrm{m}^{3}$ for the carbon

Exxon Biomedical Sciences Inc, East Millstone, New Jersey, United States.

Reprint requests to: Dr John F Gamble, Exxon Biomedical Sciences, Inc, Mettlers Road, CN 2350, NJ 08875 — 2350, United States. [E-mail: jfgambl@fpe.erenj.com] 
disulfide $\left(\mathrm{CS}_{2}\right)$ fraction of total particulate $\left(\mathrm{CS}_{2} \mathrm{~F}\right)$ among Norwegian pavers. Chase et al (8) reported increased complaints from workers when the supply of asphalt ballast was changed in the manufacture of fluorescent lights. The concentrations ranged from 0.5 to $1.3 \mathrm{mg} / \mathrm{m}^{3}$ "asphalt". However, there was no description of the sampling method, no exposure-response analysis, and no identification of any etiologic agents.

When the present study was initiated, the only epidemiologic study that had evaluated exposure-response gradients was that concerning Norwegian road maintenance workers (7). In brief, the Norseth et al study reported that symptoms of abnormal fatigue, reduced appetite, laryngeal or pharyngeal irritation, and eye irritation were more common among asphalt pavers than in a comparison group of nonasphalt-exposed highway maintenance workers. These symptoms were consolidated for analysis and called the "symptom sum." Measures of personal exposure were collected on a group of 79 pavers to correlate the symptom sum and exposure. The statistically significant correlations ( $r$ ) were with ethylbenzene $(r=0.23), 1,2,4$ trimethylbenzene $(r=0.31)$, isopropyl benzene $(r=0.28)$, and asphalt temperature $(r=0.22)$. The correlation with the $\mathrm{CS}_{2}$ fraction of total particulate was $0.13(\mathrm{P}=0.26)$. Grouping workers by average fume exposure $\left(\mathrm{CS}_{2} \mathrm{~F}\right)$ was suggestive of a threshold of $0.4 \mathrm{mg} /$ $\mathrm{m}^{3}$ for increased symptoms. Norseth et al (7) recommended that asphalt temperatures be kept below $150^{\circ} \mathrm{C}$ and the $\mathrm{CS}_{2}$ fraction below $0.40 \mathrm{mg} / \mathrm{m}^{3}$ to reduce the occurrence of symptoms. They did not consider the statistically significant correlations with solvents to be biologically plausible because of the very low $(<21 \mathrm{ppb})$ concentrations.

The results of the Norseth et al study are difficult to interpret for several reasons. First, exposure was based on a weekly average. Symptoms were recorded as the number of days when each of a dozen or more symptoms occurred and were collected only at the end of the week. The specific day of the week a symptom occurred could not be associated with that day's exposure, nor could it be determined whether the workers began work with the symptom. Second, the postulated exposure-response association with the $\mathrm{CS}_{2}$ fraction was not statistically significant when all 71 workers were included in the analysis. The $0.4 \mathrm{mg} / \mathrm{m}^{3}$ threshold was derived from a stratification of 50 open-air workers, with 7 workers in the $0.40 \mathrm{mg} / \mathrm{m}^{3}$ group. No monotonic increase in symptoms was shown by exposure group, but the sequence for the mean symptom sum was $1.4,0.9,1.5,3.0$, and 3.0 from the low to high exposure groups. Finally, after discovery of a coding error, a reanalysis of the data is underway to reassess the association with the $\mathrm{CS}_{2}$ fraction.

The study described in this report is a shift study that includes the following enhancements when compared with the Norwegian study design:
- Personal exposure samples were collected on the same day and during the same time period as the outcome measures. Added measures of asphalt fumes (such as TP, RP, VHC) and potential confounding exposures (such as ozone, heat stress, and gases) were included as part of the TWA exposure for each shift.

- Questionnaires were administered before, after, and 3 times during the shift to determine the percentage of time a worker was symptomatic. This variable was used as the symptom outcome variable.

- Changes in lung function over the shift were used as objective measures of response to exposure.

- Five segments of the asphalt industry were included. This coverage expanded the exposure characteristics of the work force.

The National Institute for Occupational Safety and Health (NIOSH) has used a similar protocol for a series of health hazard evaluations of pavers that compared effects of conventional asphalt and crumb rubber modified asphalt (9-15). Some differences from the current study included a lack of measures of before and after shift spirometry, and the exposure data were limited to total particulate $(\mathrm{TP})$, the benzene-soluble fraction of the TP (BSF), polycyclic aromatic hydrocarbons (PAH), and smoking.

In summary, this report describes a field study of 170 workers in asphalt-related occupations. The purpose is to determine the relationships between workplace exposures and acute end points (lung function tests and acute self-reported respiratory symptoms). The following two main questions have been addressed: (i) is there an association between short-term exposure to asphalt fumes and reduced lung function or increased symptoms during the day and (ii) if there is an association, what is (are) the responsible component(s) and what is (are) the exposureresponse relationship $(\mathrm{s})$ ?

\section{SUBJECTS AND METHODS}

The study was usually conducted for 2 days at each site, with the same workers participating both days. The following five industry segments were included: hot mix asphalt manufacturing, hot mix asphalt paving operations, asphalt distribution terminals, roofing manufacturing, and roofing application. At the roofing manufacture sites, workers with the highest exposure to asphalt fumes plus a sampling of workers from less-exposed areas (eg, the warehouse) were invited to participate, up to a maximum of about $12-13$ participants. For other sites, all available workers were included.

Each worker was monitored for a series of exposures and responses on each day of participation. Appendix I 
provides a summary of the measured parameters, and appendix II gives a list of the abbreviations and terms used in this text.

\section{Exposure measures}

Personal monitors were used to measure the average concentration of contaminants in the breathing zone of each participant. They were placed in the breathing zone at the beginning of each workshift after the administration of a health questionnaire and lung function test. Personal samplers were worn by each of the participants for the entire work shift and were removed just prior to the postshift spirometry measurements (providing approximate 8hour or full-shift samples). Personal air monitoring samples were collected via 2 methods [ie, active sampling trains (pumps, filters and sorbent tubes) and passive diffusion badges or tubes].

All the sampling equipment was calibrated both preand postshift and inspected at approximately 2-hour intervals during each sampling period. A summary of the methods is presented in table 1 .

\section{Response indicators}

Prior to beginning work all the volunteers were informed about the study, and they signed a consent form. Each participant's height and weight were measured, and a questionnaire was filled out on acute preshift symptoms to determine the preshift status of the 15 symptom responses. A minimum of 3 forced expiratory maneuvers into a spirometer was obtained. The largest forced vital capacity (FVC), forced expiratory volume in 1 second $\left(\mathrm{FEV}_{1.0}\right)$ and peak expiratory flow (PEF) were selected from curves without cough or early termination and with consistent effort. Other measures of flow were taken from an acceptable curve with the largest sum of the FVC and
$\mathrm{FEV}_{1.0}$, and up to 8 maneuvers were attempted to achieve the acceptability and reproducibility criteria of the American Thoracic Society (17). If the reproducibility criteria could not be met, the results were not excluded from the analysis so as to avoid the bias that can occur when subjects with abnormal lung functions are excluded $(17,18)$.

The Sensor Medics spirometer used for the analysis was calibrated before each session in the morning (preshift) and afternoon (postshift). Room temperature was recorded for each subject. All the lung function maneuvers were administered by the same NIOSH-certified technician. The percentages of change were measured as 100 times the pulmonary function test (PFT) change divided by the preshift value, with a negative value indicating a reduction in the PFT over the shift.

Symptom questionnaires were administered 3 times during the shift, as well as pre- and postshift. The acute irritant questionnaire was modified in accordance with an instrument used in a study of workers exposed to sodium borate $(19,20)$. Questions were asked about symptoms assessed by Norseth (7), as were also several "dummy" questions (eg, difficulty swallowing, ringing in ears) for which no association with exposure was expected.

\section{Data analysis}

As checks for the validity of the PFT, the age- and heightadjusted maximum $\mathrm{FEV}_{1.0}$ and $\mathrm{FVC}$ were compared with published values from the literature. The literature values were for a nonsmoking asymptomatic reference population characterized by the presence or absence of selfreported chronic respiratory symptoms.

The primary analytic strategy was to utilize both parametric and nonparametric statistics. The familiar parametric statistics include the results of ordinary least squares regression for the PFT and logistic regressions for symptoms. Parametric statistics were considered less useful in this study as they rely on assumptions of

Table 1. Methods used to collect exposure samples. (NIOSH = National Institute for Occupational Safety and Health)

\begin{tabular}{ll}
\hline Exposure & Method \\
\hline Total particulate (TP) & Modified NIOSH method 0500 (16) \\
Benzene-soluble fraction of TP (BSF) & Modification of NIOSH method 5023 (16) \\
Respirable particulate (RP) & NlOSH method 0600, modified by use of a preweighed polytetrafluoro- \\
ethylene filter and a 2-piece polystyrene cassette & Modified version of NIOSH methods 1500 and 1501, using charcoal \\
Volatile hydrocarbons (VHC) & as part of the TP sampling train and a 1 V/min sampling rate \\
Nitrogen dioxide, sulfur dioxide, hydrogen sulfide & Chemair passive diffusion monitor \\
Formaldehyde & GMD passive formaldehyde monitor \\
Carbon monoxide & Draeger 50/a-D direct reading colorimetric passive dosimetry tube \\
Background ozone & Factory calibrated Dasbi model 1003-AH 0zone analyzer \\
Wet bulb globe temperature (WBGT) & Reuter-Stokes R55-2110 heat stress monitor \\
\hline
\end{tabular}


linearity, no threshold, and a particular distribution of observations (usually a normal distribution) for each statistical model.

Nonparametric statistics was considered the more important analysis in this study. Nonparametric techniques, unlike parametric techniques, do not require any assumptions about variable distributions, the form of the exposure-response model, or the presence or absence of a threshold. The results of these analyses are represented graphically, rather than as the typical regression coefficients, risk ratios, and P-values of parametric statistics.

Additional analyses were performed to assess the effect of the repeated measures aspect of the data. The results clearly indicated no meaningful differences in the within-person and person-to-person variation. On the basis of these results, the subsequent analyses ignored the repeated-measure aspects of the data.

An outline of the analytic strategies used to assess exposure-response during the shift is presented in table 2 , and these strategies are discussed further later.

\section{Pulmonary function measures before and after work}

The changes in the PFT measures over the shift were used to evaluate the possible exposure-response relationships between the 4 PFT measures and the asphalt fume exposures with possible confounding variables being accounted for.

Continuous responses: least-squares regression. We conducted a standard least-squares regression analysis with the changes in the $\mathrm{FEV}_{1.0}, \mathrm{FVC}, \mathrm{FEF}_{25-75}$, and PEF as the dependent variables. The independent variables were demographic (site, race, gender, age, height, weight, and smoking status) and exposure (TP, RP, BSF, formaldehyde, VHC, carbon dioxide, sulfur dioxide, hydrogen sulfide, carbon monoxide and total cigarettes smoked on the study day). The parametric statistical-model assumption of normality-distributed residuals was assessed by Wilks' test, and the dependent variables were transformed using Blom's transformation (21) where necessary. The adequacy of the model was tested by plotting the model residuals against the independent variables to assure there were random patterns.

Continuous responses: nonparametric regression. Locally weighted scatterplot smoothing (LOWESS) (22) was generated for the $4 \mathrm{PFT}$ responses against $\mathrm{TP}$, volatile hydrocarbons (VHC), BSF, respirable particulate (RP), cigarettes smoked during shift, hours worked, VHC + TP and $\mathrm{VHC}+\mathrm{BSF}$ as the exposure measures. In addition, a projection pursuit regression technique (23) was used with the change in $\mathrm{FEV}_{1.0}$ and several of the independent variables. This is a multivariate nonparametric approach analogous to multivariate parametric regression techniques. These nonparametric approaches have an advantage over least-squares regression and analysis of variance in that no assumption is necessary about the shape of an exposure-response association. As a result, the presence or absence of a threshold can be determined visually. Confidence intervals were generated for the LOWESS regressions using the bootstrap technique (24). A fuller discussion of these methods is available from the authors.

Dichotomous responses: logistic regression. Logistic regression was used to assess whether the exposure was associated with biologically important changes in PFT among the susceptible workers by evaluating the exposure-response, where the response variable was a cutpoint below which the PFT might be considered "adverse" on an individual level. In this report, an "adverse" effect was considered to be a decrement of greater than $10 \%$ for a change in $\mathrm{FEV}_{1.0}$ and FVC, and greater than $15 \%$ for a change in PEF and $\mathrm{FEF}_{25-75}(25-32)$.

Table 2. Analytic strategy used for the study.

\begin{tabular}{|c|c|}
\hline Analysis & Comments \\
\hline $\begin{array}{l}\text { Analyzis of changes in pulmonary function test (spirometry) (PFT) measures } \\
\text { over the shift ( } \triangle P F T)\end{array}$ & $\begin{array}{l}\text { Investigate or test for exposure-response functions for exposure } \\
\text { measures versus objective lung function measures, with consideration } \\
\text { of potential confounders }\end{array}$ \\
\hline \multicolumn{2}{|l|}{ Continuous responses } \\
\hline Least-squares regression & $\begin{array}{l}\text { Analysis with and without considering repeated measures aspect of } \\
\text { subjects }\end{array}$ \\
\hline Nonparametric regression & No assumption of model-specific exposure-response \\
\hline \multicolumn{2}{|l|}{ Dichotomous responses } \\
\hline Logistic regression & $\begin{array}{l}\text { Employ a cutpoint below which pulmonary function could be considered } \\
\text { "adverse" }\end{array}$ \\
\hline Analysis of symptoms during shift & $\begin{array}{l}\text { Investigate or test for exposure-respnse functions for exposure } \\
\text { measures versus irritation symptoms, with consideration of potential } \\
\text { confounders }\end{array}$ \\
\hline Individual symptoms and symptom sum & $\begin{array}{l}\text { Calculate a score for each of } 15 \text { symptoms for each subject, and a } \\
\text { summary measure for individuals }\end{array}$ \\
\hline Logistic regression & Separate analyses, for several of the symptoms and the symptom sum \\
\hline Nonparametric regression & Analysis of symptom sum without assumption of model form \\
\hline
\end{tabular}


Logistic regression analyses were employed using the dichotomous PFT variables as the dependent variables and the asphalt fume components and confounders as independent continuous variables.

\section{Symptoms during the shiff}

Only incident symptoms that arose during the work shift were included in the exposure-response analysis. The worker was asked if he or she was experiencing (or had experienced since the previous interview that day) any of 15 symptoms, and whether the symptoms, if present, were mild, moderate, or severe. The interview was conducted at 5 time points: at the start of the shift, 2 hours, 4 hours, and 6 hours into the shift and at the end of the shift. If a worker began the shift with a particular symptom, the presence of that symptom was not counted until he or she experienced at least 1 period without the symptom; for the initial symptoms neither the symptom nor the time periods were counted in the final response measure. If there were any missing data for a period, no score was calculated for that subject and symptom for that day.

The resulting symptom score was the incidence of each symptom expressed as a fraction between 0 and 1 (hours with symptom/hours at risk). For example, if a worker developed a symptom only during the last 2 hours of the shift and did not have the symptom during the first 6 hours of the shift, the score was 0.25 (2/8). If the worker came to work with the symptom and did not have it at the end of the first 2-hour segment, but developed it during the last 2 hours of the shift, the score was $0.33(2 / 6)$.

An overall symptom sum was generated as the sum of the 15 individual symptom scores with a potential range from zero (no symptoms all day) to 15 (all symptoms all day). The symptom sum may have been inappropriate, as it included a wide variety of symptoms, some of which had a different etiology and thus reduced the likelihood of detecting an exposure-response trend. However, because of the low incidence of symptoms overall, the symptom sum was an attempt to increase the statistical power of the analysis, and it is, in some ways, analogous to the symptom sum used by Norseth et al (7).

Individual symptom and symptom sum: logistic regression. A series of cumulative odds logistic regressions [Armstrong \& Sloan (33), also known as a proportional odds model by McCullagh \& Nelder (34)] was performed with the symptom sum or the individual symptom score as the dependent variable, and the 17 asphalt fume components and potential confounders as independent variables. The discrete form of the model was used so that a specific response form did not need to be assumed.

For the symptom sum the responses were categorized into 6 groups of roughly equal frequency $(\mathrm{k}=6)$; for the individual symptom score analyses the responses were categorized into 4 groups $(\mathrm{k}=4)$. The resulting measures from these analyses were adjusted relative risks.

Individual symptom and symptom sum: nomparametric regression. The nonparametric regression used a 2-variable locally weighted scatterplot smoothing (LOWESS) technique for symptom sum plotted against TP, RP, BSF, and VHC. A $95 \%$ confidence interval $(95 \% \mathrm{CI})$ was generated for the LOWESS plots using the bootstrap technique (24).

\section{RESULTS}

\section{Industrial hygiene findings}

The industrial hygiene exposure monitoring results are summarized in table 3 for each industry segment, and they are visually displayed in the exposure-response results. The exposure variables were generally skewed and therefore suggested a lognormal distribution. The maximum concentrations of TP, RP, BSF, and VHC were $6.16,1.38,1.32$, and $19.8 \mathrm{mg} / \mathrm{m}^{3}$, respectively. The concentrations of sulfur dioxide, nitrogen dioxide, hydrogen disulfide, and formaldehyde were near or below the

Table 3. Personal exposures and industry segment. (HMA = hot mix asphalt manufacturing, $G M=$ geometric mean , GSD = geometric standard deviation)

\begin{tabular}{|c|c|c|c|c|c|c|c|c|c|c|c|c|c|c|c|}
\hline \multirow[b]{3}{*}{ Total } & \multicolumn{3}{|c|}{ HMA $(\mathrm{N}=20)$} & \multicolumn{3}{|c|}{$\begin{array}{l}\text { Asphalt distribution } \\
\text { terminals }(\mathrm{N}=47)\end{array}$} & \multicolumn{3}{|c|}{$\begin{array}{l}\text { Roofing manu- } \\
\text { facturing }(\mathrm{N}=77)\end{array}$} & \multicolumn{3}{|c|}{$\begin{array}{c}\text { Roofing } \\
\text { application ( } \mathrm{N}=60)\end{array}$} & \multicolumn{3}{|c|}{$\begin{array}{l}\text { HMA paving } \\
\text { operations }(\mathrm{N}=80)\end{array}$} \\
\hline & GM & GSD & Maximum & GM & GSD & Maximum & GM & GSD & Maximum & GM & GSD & Maximum & GM & GSD I & aximum \\
\hline & 0.45 & 1.91 & 1.31 & 0.19 & 2.43 & 2.51 & 0.60 & 2.18 & 6.16 & 0.34 & 3.05 & 2.73 & 0.33 & 2.18 & 1.66 \\
\hline $\begin{array}{l}\text { Respirable } \\
\text { particulate (RP) } \\
\text { Benzene-soluble }\end{array}$ & 0.10 & 2.53 & 0.60 & 0.06 & 1.66 & 0.16 & 0.08 & 2.23 & 0.56 & 0.14 & 2.52 & 1.38 & 0.10 & 2.78 & 1.08 \\
\hline $\begin{array}{l}\text { Benzene-soluble } \\
\text { fraction (BSF) }\end{array}$ & 0.06 & 1.74 & 0.14 & 0.05 & 2.07 & 1.32 & 0.08 & 2.23 & 1.32 & 0.12 & 2.71 & 1.23 & 0.09 & 2.57 & 0.65 \\
\hline $\begin{array}{l}\text { Volatile hydro- } \\
\text { carbons (VHC) }\end{array}$ & 1.06 & 2.40 & 6.28 & 1.58 & 3.41 & 19.80 & 0.70 & 2.26 & 8.73 & 0.30 & 4.41 & 6.71 & 0.38 & 4.75 & 7.72 \\
\hline
\end{tabular}


level of detection. Data below the limit of detection were replaced by the limit of detection divided by the square root of 2. (The mean exposures are summarized in appendix III by job groupings in each industry segment and are available in more detail from the authors.)

Ozone data were collected in the general work area but away from the asphalt fume sources. For inside operations, such as sites manufacturing asphalt roofing material, the ozone data were from inside the work area. For outside work segments, such as paving and roofing, the ozone data represent outside ambient air. The maximum ozone level was $92 \mathrm{ppb}$, which occurred at a roofing application site in July. The TLV® for ozone is 100 ppb (ceiling).

Wet bulb globe temperature (WBGT) readings were taken outside, in sunlight if the subjects were working outside. The TLV® values for heat exposure vary depending on the work load. For continuous work with a heavy work load (eg, pick and shovel work), the TLVB is $77^{\circ} \mathrm{F}\left(25^{\circ} \mathrm{C}\right)$. For a continuous moderate work load (walking about with moderate lifting and pushing), the TLVB is $80^{\circ} \mathrm{F}\left(27^{\circ} \mathrm{C}\right)$. For a continuous light work load (sitting or standing to control machines, light hand or arm work), the TLV(B is $86^{\circ} \mathrm{F}\left(30^{\circ} \mathrm{C}\right)$. Asphalt jobs can cover the full-range of physical activity.

During 33 days of the data collection heat exposure was above the TLVß values on several occasions, as noted in table 4.

\section{Study population: descriptive}

Table 5 presents personal, demographic, and symptom information for all the subjects. There was a total of 170 subjects, 7 of whom were women. One-third of the cohort was black, and two-thirds were white or Hispanic.
There were 288 person-days of observation, and the distribution of workers and number of person-days of observation by industry segment were as follows: paving (32.4\% of the subjects, 82 person-days); roofing manufacturing ( $25.3 \%$ of the subjects, 77 person-days); roofing application ( $21.8 \%$ of the subjects, 62 person-days); terminals ( $14.1 \%$ of the subjects, 47 person-days); and hot-mix asphalt manufacturing (6.5\% of the subjects, 20 person-days). There were only small differences in the mean age, height, and weight between industry segments. Nearly $60 \%$ of roofers were black, followed by $40 \%$ in roofing manufacturing, $24 \%$ in paving, $17 \%$ in terminals, and $9 \%$ in hot-mix asphalt manufacturing facilities. The number of nonsmokers and smokers overall was similar ( $42.4 \%$ and $38.8 \%$, respectively) with only $32(18.8 \%)$ being ex-smokers. However, the smoking prevalence varied as follows by industry segment: hot-mix asphalt manufacturing $=54 \%$; roofing application and manufacturing $=43 \%$ and $44 \%$; paving $=38 \%$; terminals $=17 \%$.

The average base-line values for $\mathrm{FEV}_{1.0}$ and $\mathrm{FVC}$ were slightly above the expected values for all the smoking categories except the $\mathrm{FEV}_{1.0}$, which was $93 \%$ of the predicted (race-, age- and height-adjusted); this finding indicates some airway obstruction among the smokers, as expected.

The mean percentage of time (average symptom score) the workers were symptomatic ranged from $<1 \%$

Table 4. Cases of excessive heat during 33 days of the data collection.

\begin{tabular}{lcl}
\hline $\begin{array}{l}\text { Threshold limit values } 8 \\
\text { for continuous work }\end{array}$ & $\begin{array}{c}\text { Days } \\
(\mathrm{N})\end{array}$ & Sites \\
\hline Heavy work $\left(77^{\circ} \mathrm{F} ; 25^{\circ} \mathrm{C}\right)$ & 13 & $\begin{array}{l}5 \text { paving, } 5 \text { roofing application, } \\
3 \text { roofing manufacturing }\end{array}$ \\
Moderate work $\left(80^{\circ} \mathrm{F} ; 27^{\circ} \mathrm{C}\right)$ & 11 & $\begin{array}{l}2 \text { roofing manufacturing, 5 } \\
\text { roofing application, } 5 \text { paving }\end{array}$ \\
Light work $\left(86^{\circ} \mathrm{F} ; 30^{\circ} \mathrm{C}\right)$ & 6 & 2 paving, 4 roofing application \\
\hline
\end{tabular}

Table 5. Summary of demographic characteristics of the asphalt worker cohort. (FEV ${ }_{1.0}=$ forced expiratory volume in 1 second, $F V C=$ forced vital capacity)

\begin{tabular}{|c|c|c|c|c|c|c|c|c|c|}
\hline & \multicolumn{9}{|c|}{ All } \\
\hline & \multirow[t]{2}{*}{ Na } & \multirow[t]{2}{*}{$\%$} & \multirow[t]{2}{*}{ Mean } & \multirow[t]{2}{*}{$S D$} & \multirow[t]{2}{*}{ Range } & \multicolumn{2}{|c|}{ Predicted FEV ${ }_{1.0}(\%)$} & \multicolumn{2}{|c|}{ Predicted FVC (\%) } \\
\hline & & & & & & Mean & SD & Mean & SD \\
\hline \multicolumn{10}{|l|}{ Gender } \\
\hline Female & 7 & 4.1 & . & . & . & & . & . & . \\
\hline Male & 163 & 95.9 & . & . & . & & . & . & . \\
\hline \multicolumn{10}{|l|}{ Race } \\
\hline White & 107 & 62.9 & . & . & . & & . & . & . \\
\hline Black & 56 & 32.9 & . & . & . & . & . & . & . \\
\hline Other & 7 & 4.2 & & & & . & . & . & . \\
\hline Age & . & . & 38.6 & 12.6 & $18-76$ & . & . & . & . \\
\hline Hours worked & . & . & 8.5 & 1.7 & $4.5-17.5$ & . & . & . & . \\
\hline \multicolumn{10}{|l|}{ Smoking } \\
\hline Nonsmoker & 72 & 42.4 & . & . & . & 100 & 16.9 & 102 & 16 \\
\hline Ex-smoker & 32 & 18.8 & . & . & . & 100.8 & 19.2 & 108.7 & 16.6 \\
\hline Smoker & 66 & 38.8 & . & . & . & 93.2 & 15.4 & 102.0 & 11.7 \\
\hline
\end{tabular}

a Number of study participants $=170$. 
Table 6. Mean symptom scores for the asphalt cohort. (Percentage of time with symptoms)

\begin{tabular}{lc}
\hline Symptom & Mean symptom score (\%) \\
\hline Eye irritation & 3.1 \\
Nose irritation & 4.1 \\
Three or more sneezes in a row & 2.4 \\
Nosebleed & 0.4 \\
Throat irritation & 5.4 \\
Coughing & 5.4 \\
Difficulty in breathing & 3.2 \\
Headache & 4.5 \\
Dizziness & 1.2 \\
Nausea & 1.1 \\
Itching skin & 1.1 \\
Ringing in ears & 0.9 \\
Unusually tired & 2.0 \\
Loss of appetite & 0.5 \\
Difficulty swallowing & 0.3 \\
\hline
\end{tabular}
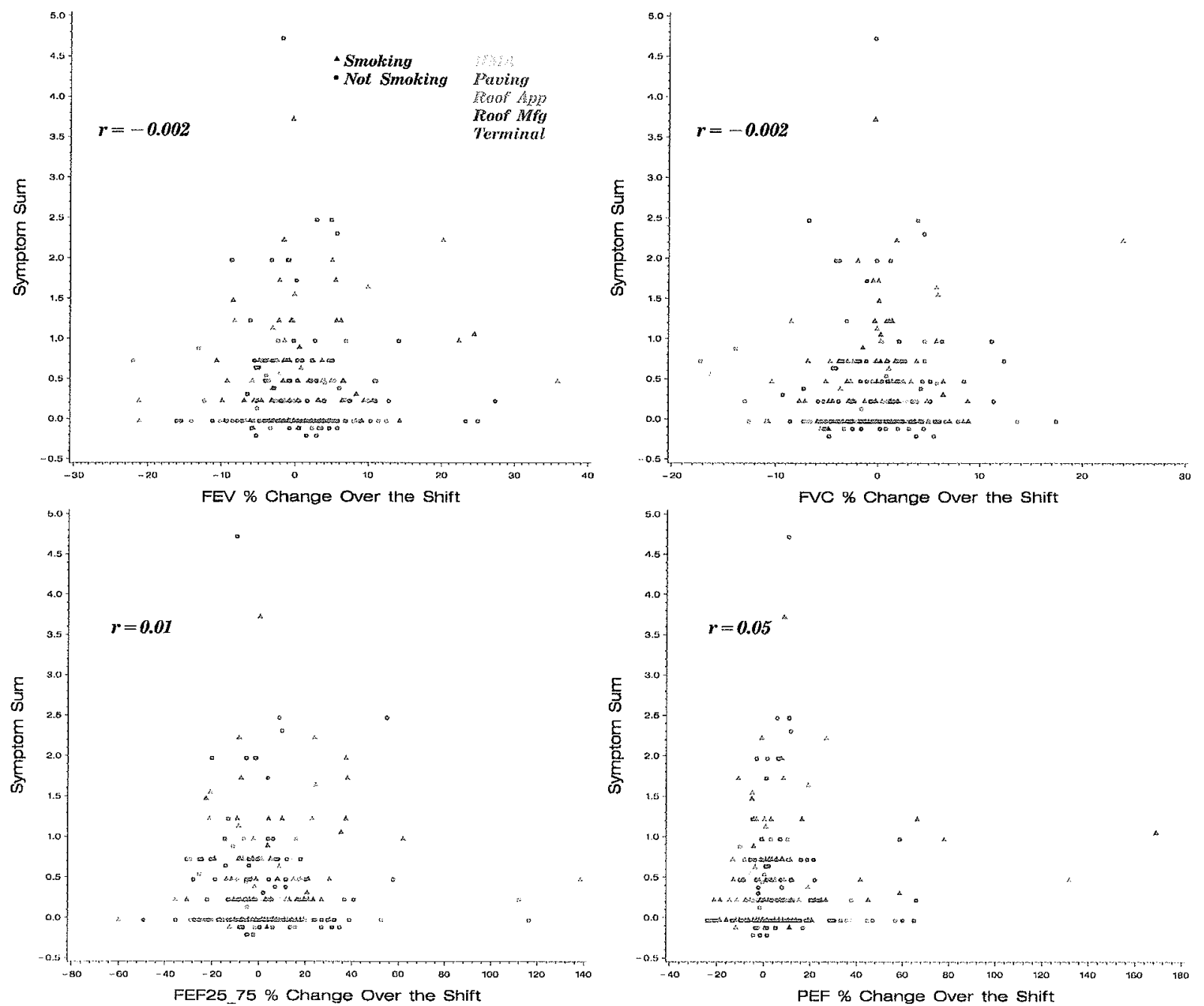

Figure 1. Symptom sum versus the percentage of change in the forced expiratory volume in 1 second (FEV\%), the percentage of change in the forced vital capacity (FVC\%), the percentage of change in the average forced expiratory flow rate between $25 \%$ and $75 \%$ of the $\mathrm{FVC}$ ( $\left(\mathrm{FEF}_{25}-75 \%\right.$ ), and the percentage of change in the peak expiratory flow rate (PEF\%) with the Kendall correlation coefficients. (See appendix 3 for an explanation of the industry segments)

to $5.4 \%$. The lowest symptom rates $(<2 \%)$ included swallowing difficulty, nosebleeds, loss of appetite, ringing ears, and nausea. Note that ringing ears and difficulty swallowing were "dummy" variables that were thought to be unrelated to exposure. The most common symptoms ( $>3 \%$ ) included breathing difficulty, nose irritation, headache, throat irritation, and coughing (table 6). Practically all the symptoms were mild in severity, and none showed any association with a reduction in lung function over the shift (figure 1). (Data on individual symptom scores are available from the authors.)

\section{Exposure-response findings}

The purpose of this section was to determine whether any associations existed between the measures of response

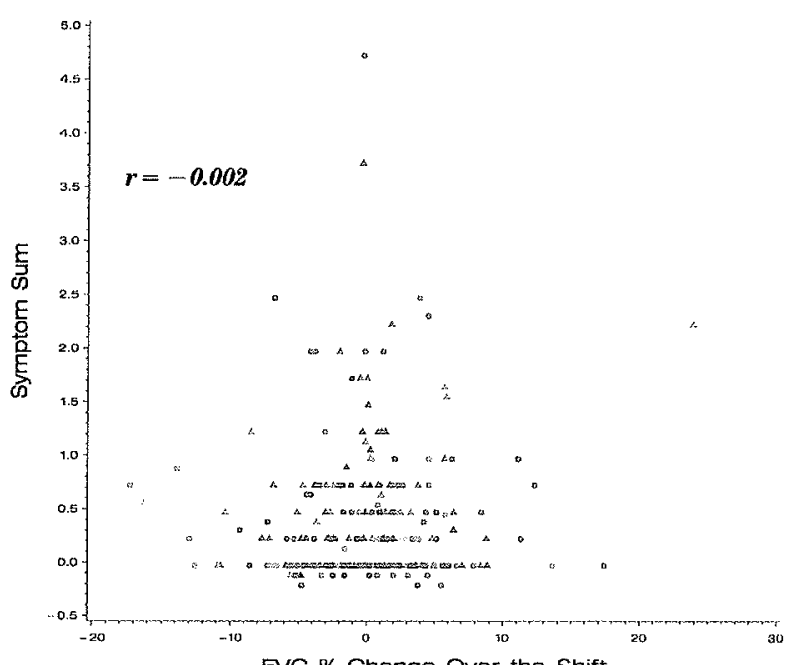


(PFT change, symptoms) and the measures of asphalt fumes (eg, TP, RP, BSF, VHC) while accounting for potential confounding variables (eg, cigarettes smoked during the shift, nitrogen dioxide). A causal association was considered likely if there was a trend for reduction in lung function (or an increase in symptoms) as exposure increased. In this type of internal comparison, "referents" are the persons with minimal-to-low exposure. The changes in $\mathrm{FEV}_{1.0}$ was considered the most important PFT measure of effect, and BSF and VHC were the most specific measures of asphalt fumes.

When independent variables are highly correlated, it is difficult to disentangle individual effects. In addition, if nonasphalt pollutants (eg, cigarette smoke) cause a measurable response or are at relatively high concentrations, it may be difficult to evaluate individual effects. The largest correlation coefficient $(r)$ between the independent variables was 0.51 for sulfur dioxide and nitrogen dioxide. However, since the concentrations for these 2 variables were generally at or below the limit of detection, any response associated with them would have been too small to measure reliably. The correlations between RP and BSF, TP and BSF, TP and RP were 0.44, 0.47, and 0.47 , respectively. Thus the effects of these exposure measures were not completely independent. The change in $\mathrm{FEV}_{1.0} \%$ and $\mathrm{FEF}_{25-75} \%$ had a correlation of 0.70 , so, to some extent, these 2 measures of lung function measured a similar response. The preceding correlations are nonparametric Kendall correlations, which are based on ranks.

\section{Changes in the pmulmonary function tests over the shift}

\section{Continuous responses}

Least-squares regression. This parametric technique evaluates whether there is a relationship between individual measures of changes in PFT and the combined exposure variables while adjusting for potentially confounding variables. The modeling results are presented in table 7 on pages $194-195$.

The changes in the $\mathrm{FEV}_{1.0}, \mathrm{FEF}_{25-75}$, and PEF measures were transformed by Blom's method to achieve a normal distribution of the residuals. The change in the FVC was the only response variable with a statistically significant model $\mathrm{F}$ statistic $(\mathrm{P} \leq 0.05)$. However, all 17 independent variables only explained $17 \%$ of the variance in the change in FVC (model $\mathrm{R}^{2}=0.17$ ). The variables VHC and sulfur dioxide were dropped from the model to achieve a larger sample size $(\mathrm{N}=245)$; the resulting $\mathrm{R}^{2}$ was 0.14 . In both the full and reduced models the only significant term was the worker's age $(\mathrm{P}<0.001$ and $\mathrm{P}<0.0002$ ) (ie, there was no exposure variable significantly associated with the change in FVC or any other measure of the change in PFT).

No apparent association between the asphalt exposures and changes in pulmonary function were observed, and the model $\mathrm{R}^{2}$ values were generally $<0.15$, indicating that the independent exposure variables in the model provided little information to explain the variability in the PFT response.

Nonparametric regression. The LOWESS regression analyses assessed the relationship between the 4 measures of change in PFT considering only 2 variables at a time; no adjustment for confounders was possible. However, no consistent reductions in the PFT were associated with any exposure variable or potentially confounding variable. The possible exceptions have been visually displayed in figures $2-5$ on pages 194-197, and they have been summarized in words.

The $\mathrm{FEV}_{1.0}$ was reduced $\sim 5 \%$ at $\mathrm{BSF}$ concentrations greater than $0.6 \mathrm{mg} / \mathrm{m}^{3}$ due to 3 data points at concentrations of 1.1 to $1.32 \mathrm{mg} / \mathrm{m}^{3}$. The highest concentration was $1.34 \mathrm{mg} / \mathrm{m}^{3}$ in roofing manufacturing, but the $\mathrm{FEV}_{1.0}$ for this worker increased $3 \%$ over the shift. The $\mathrm{FEV}_{1.0}$ was reduced about $1-3 \%$ at VHC concentrations between about 6 and $18 \mathrm{mg} / \mathrm{m}^{3}$. However, the $95 \%$ bootstrap confidence intervals always included a change in $\mathrm{FEV}_{1.0} \%$ of zero, except for VHC concentrations between about 6 and $16 \mathrm{mg} / \mathrm{m}^{3}$. Nine of the 14 observations at VHC concentrations above $6 \mathrm{mg} / \mathrm{m}^{3}$ were for terminal workers, some of whom were office workers (including the maximum VHC concentration).

The FVC was reduced about $3 \%$ at VHC concentrations of $>10 \mathrm{mg} / \mathrm{m}^{3}$, VHC + BSF concentrations of $>8$ $\mathrm{mg} / \mathrm{m}^{3}$ and $\mathrm{VHC}+\mathrm{TP}$ concentrations of $>12 \mathrm{mg} / \mathrm{m}^{3}$, with 4,6 , and 6 observations, respectively. The regression curves for the change in $\mathrm{FEF}_{25-75}$ and $\mathrm{PEF}$ never dropped below the zero change.

There were no reductions in PFT associated with either cigarettes smoked during the shift or hours worked during the shift. No association was observed between the change in PFT and the mean and maximum values for the independent variables of ozone and WBGT. These data for the change in $\mathrm{FEV}_{1.0} \%$ are displayed in figure 6 (page 198). The concentration of the other gases (nitrogen dioxide, sulfur dioxide, formaldehyde, hydrogen disulfide) were considered too low to produce a reduction in lung function, and carbon monoxide had no direct effect on lung function.

No consistent decreases in pulmonary function (TP, RP, BSF, and VHC) were associated with increases in individual measures of exposure to asphalt fumes.

Projection pursuit nonparametric analysis. Multivariate nonparametric regression analyses (23) were used to test for the effects of several exposure variables 
Table 7. Least squares regression results - analysis of variance for 4 responses, all independent variables. $\left[F E V_{1.0}=\right.$ forced expiratory volume in $1 \mathrm{~s}$, FVC

\begin{tabular}{|c|c|c|c|c|c|}
\hline \multirow[t]{3}{*}{ Source } & \multirow{3}{*}{$\begin{array}{l}\text { Degrees } \\
\text { of } \\
\text { freedom }\end{array}$} & \multicolumn{4}{|c|}{$\Delta \mathrm{FEV}_{1}$} \\
\hline & & $\begin{array}{l}\text { Source df } \\
\text { Model } 22 \\
\text { Error } 168 \\
\text { Total } 190\end{array}$ & $\begin{array}{c}\text { F value } \operatorname{Pr}>F \\
1.230 .23 \\
\text { R-Sq }=0.14\end{array}$ & $\begin{array}{l}\text { Source df } \\
\text { Model } 20 \\
\text { Error } 224 \\
\text { Total } 244\end{array}$ & $\begin{array}{c}\text { F value } \mathrm{Pr}>\mathrm{F} \\
1.360 .15 \\
\mathrm{R}-\mathrm{Sq}=0.11\end{array}$ \\
\hline & & F value & $\mathrm{Pr}>\mathrm{F}$ & F value & $\mathrm{Pr}>\mathrm{F}$ \\
\hline Site & 4 & 0.16 & 0.96 & 0.48 & 0.75 \\
\hline Gender & 1 & 1.54 & 0.22 & 0.91 & 0.34 \\
\hline Race & 2 & 1.56 & 0.21 & 1.82 & 0.16 \\
\hline Age & 1 & 3.73 & 0.06 & 4.63 & 0.03 \\
\hline Height & 1 & 0.10 & 0.75 & 0.78 & 0.38 \\
\hline Weight & 1 & 2.12 & 0.15 & 0.26 & 0.61 \\
\hline Smoker & 2 & 0.27 & 0.76 & 0.72 & 0.49 \\
\hline Total particulate $\left(\mathrm{mg} / \mathrm{m}^{3}\right)$ & 1 & 0.22 & 0.64 & 3.76 & 0.05 \\
\hline Respirable particulate collected using a cyclone sampler $\left(\mathrm{mg} / \mathrm{m}^{3}\right)$ & 1 & 1.25 & 0.26 & 0.24 & 0.63 \\
\hline Benzene soluble fraction of the total particulate $\left(\mathrm{mg} / \mathrm{m}^{3}\right)$ & 1 & 5.84 & 0.02 & 4.31 & 0.04 \\
\hline Formaldehyde & 1 & 0.08 & 0.78 & 0.00 & 0.97 \\
\hline Volatile hydrocarbons collected using a charcoal tube $\left(\mathrm{mg} / \mathrm{m}^{3}\right)$ & 1 & 0.15 & 0.70 & & \\
\hline Nitrogen dioxide (ppm) & 1 & 1.74 & 0.19 & 0.19 & 0.66 \\
\hline Sulfur dioxide (ppm) & 1 & 1.04 & 0.31 & . & \\
\hline Hydrogen sulfide (ppm) & 1 & 0.50 & 0.48 & 1.75 & 0.19 \\
\hline Carbon monoxide (ppm) & 1 & 0.00 & 0.96 & 1.89 & 0.17 \\
\hline Clgarettes & 1 & 0.00 & 0.97 & 0.29 & 0.59 \\
\hline
\end{tabular}
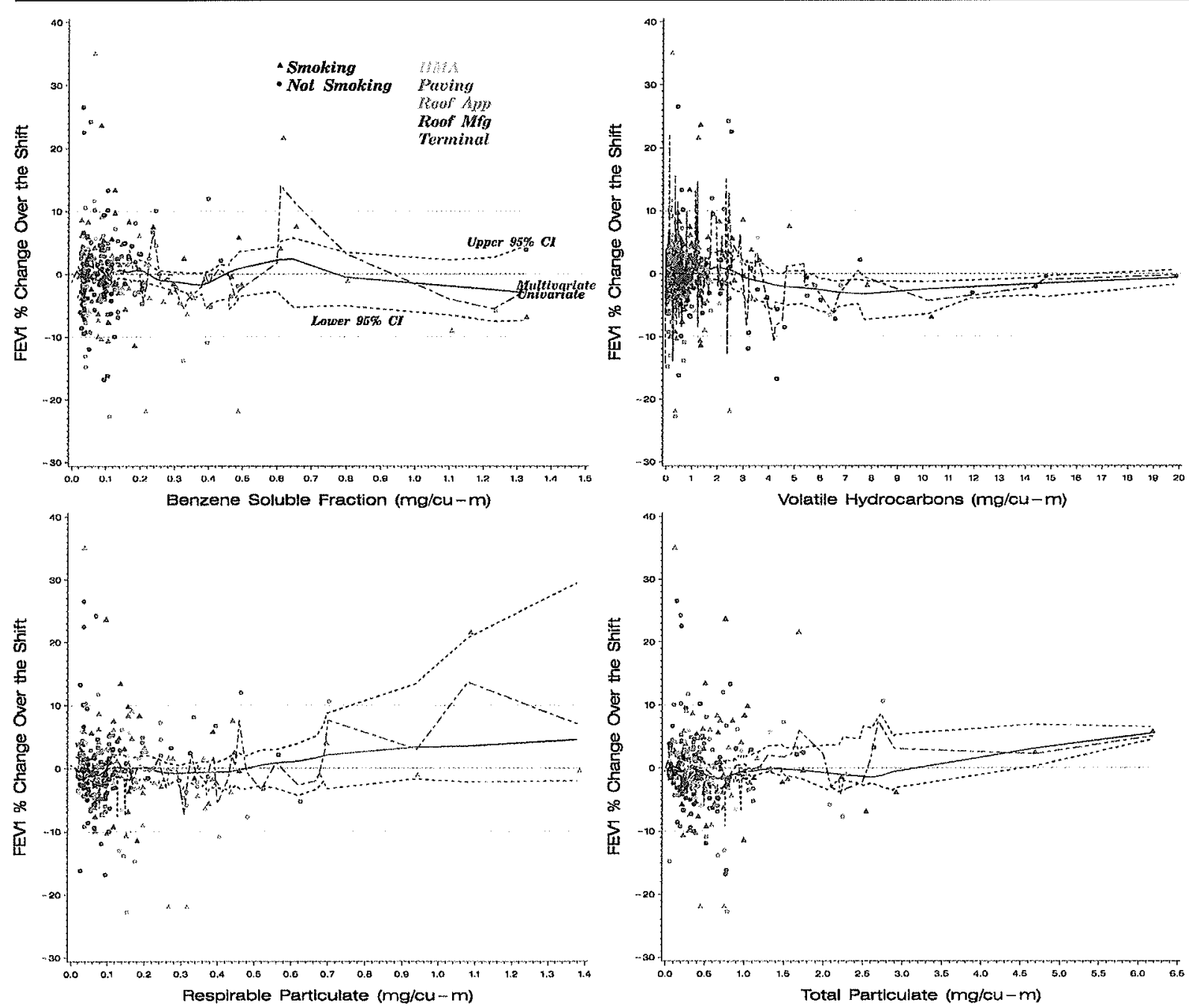

Figure 2. Univariate and multivariate nonparametric regression of the percentage of change in the forced expiratory volume in 1 second $(F E V, \%)$ versus the total particulate (TP), respirable particulate (RP), benzene soluble fraction of the TP (BSF), and volatile hydrocarbons (VHC) with the bootstrap $95 \%$ confidence interval. (See appendix 3 for explanation of industry segments.) 
sed vital capacity, $\mathrm{FEV}_{25-75}=$ average forced expiratory flow rate between $25 \%$ and $75 \%$ of $\mathrm{FVC}, \mathrm{PEF}=$ peak expiratory flow rate, $\Delta=$ change)

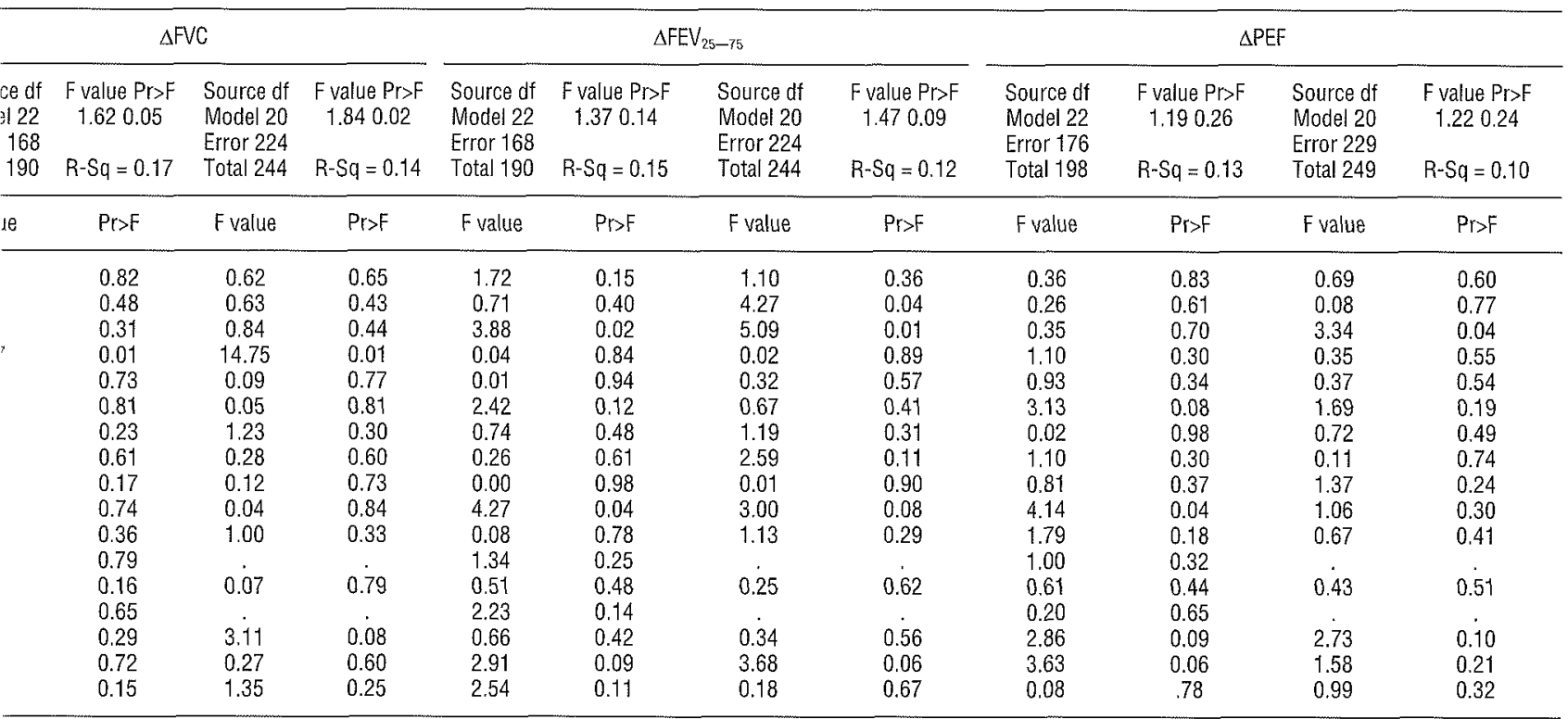
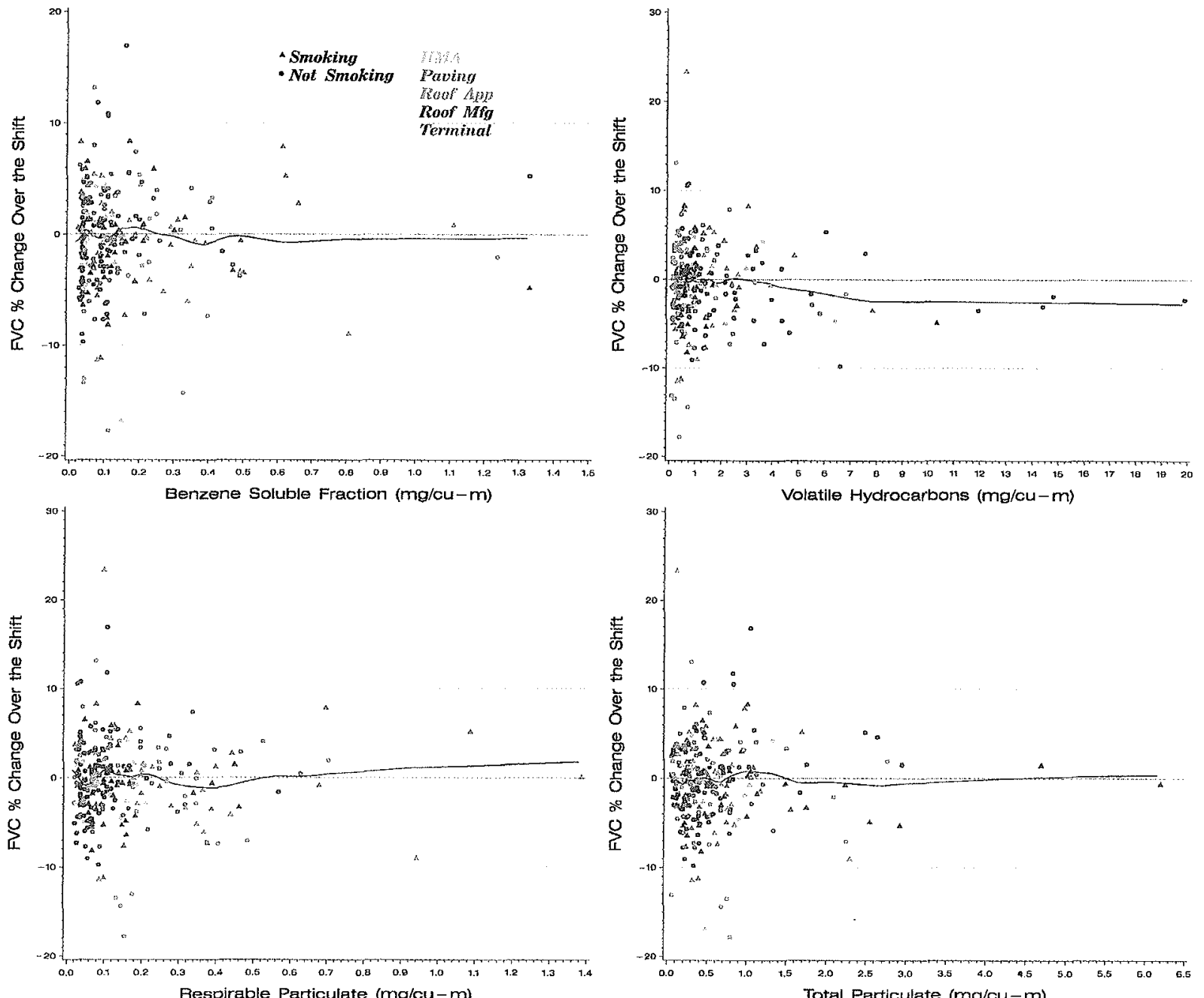

Figure 3. Univariate nonparametric regression of the percentage of change in the forced vital capacity (FVC\%) versus the total particulate (TP), respirable particulate (RP), benzene soluble fraction of the TP (BSF), and volatile hydrocarbons (VHC). (See appendix 3 for an explanation of the industry segments.) 

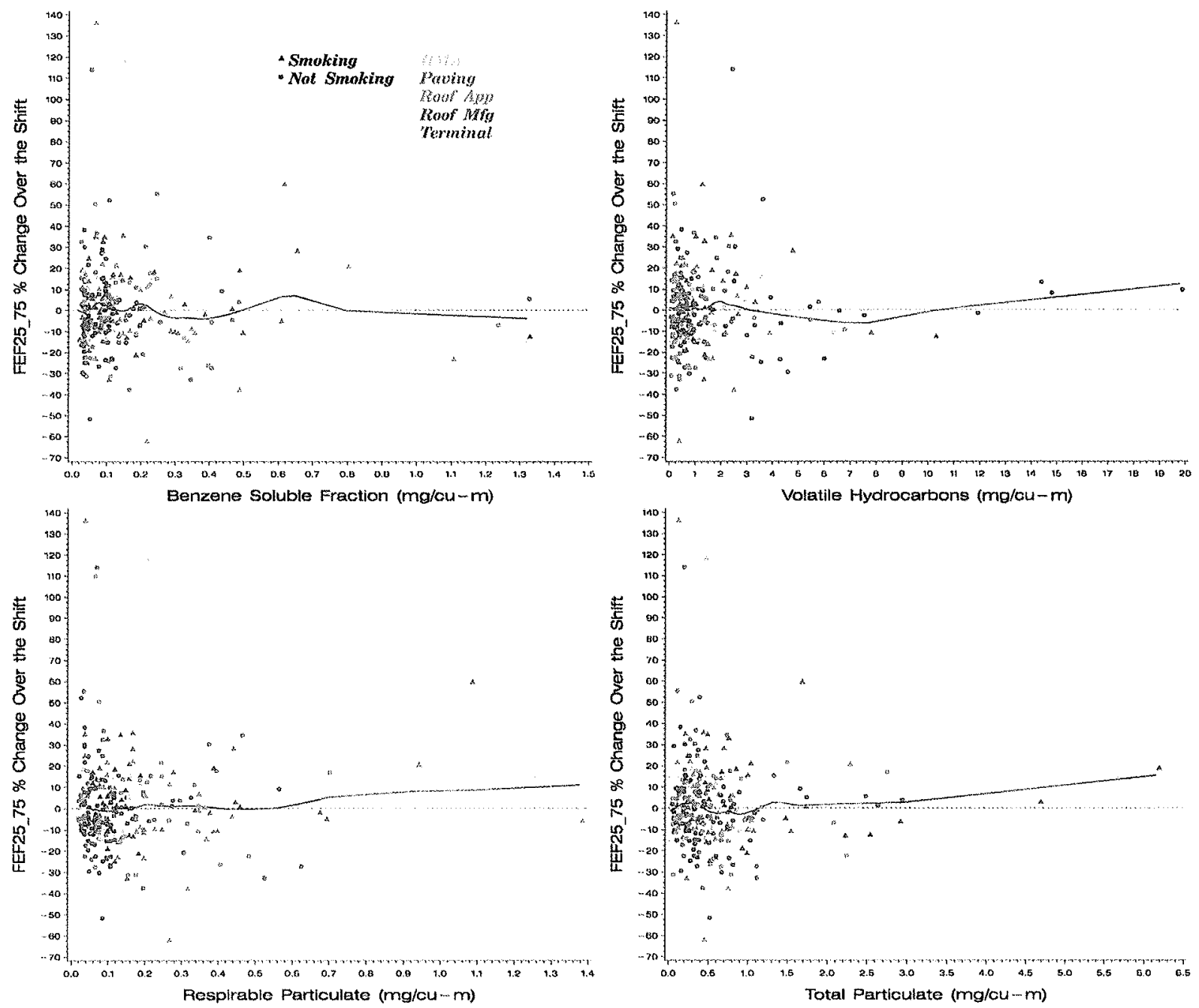

Figure 4. Univariate nonparametric regression of the percentage of change in the average forced expiratory flow rate between $25 \%$ and $75 \%$ of the forced vital capacity $\left(\mathrm{FEF}_{25-75} \%\right.$ ) versus the total particulate (TP), respirable particulate (RP), benzene soluble fraction of the TP (BSF), and volatile hydrocarbons (VHC). (See appendix 3 for an explanation of the industry segments.)

simultaneously. A model was estimated using the the change in $\mathrm{FEV}_{1.0}$ and the independent exposure variables of RP, TP, BSF, VHC, and cigarettes smoked during the shift. A plot of the projection pursuit (multivariate) predicted response for the change in $\mathrm{FEV}_{1.0} \%$ and the LOWESS (univariate) predicted response versus TP, RP, BSF, and VHC is presented in figure 2.

The model did not indicate a significant relationship between any independent exposure variable and the the change in $\mathrm{FEV}_{1.0}$. One and 2 direction models were fit, and neither form was statistically significant.

\section{Dichotomous responses}

There were relatively few workers with adverse responses below the cutpoints of $-15 \%$ for the change in $\mathrm{FEF}_{25-75}$ and PEF and of $-10 \%$ for the change in $\mathrm{FEV}_{1.0}$ and FVC (figures 2-5). The variables of site, gender, and race were dropped because "adverse" responses were not found in all categories of these variables. Because of missing data, and a low variation in the exposures, the concentrations of formaldehyde, nitrogen dioxide, and hydrogen sulfide were not included in the model either. When they were included, they gave inconsistent mathematical results (abnormally large parameter estimates and associated standard errors). Based on the score statistic (a measure of the reduction of the log likelihood), none of the models indicated statistically significant associations between the $\triangle P F T$ measures and the independent variables in the model.

No apparent associations were observed between "adverse" reductions in pulmonary function and exposure to any measured exposure variables.

\section{Symptoms duing the shift}

The severity of the symptoms could not be analyzed as most of the symptoms were absent or mild in nature. 

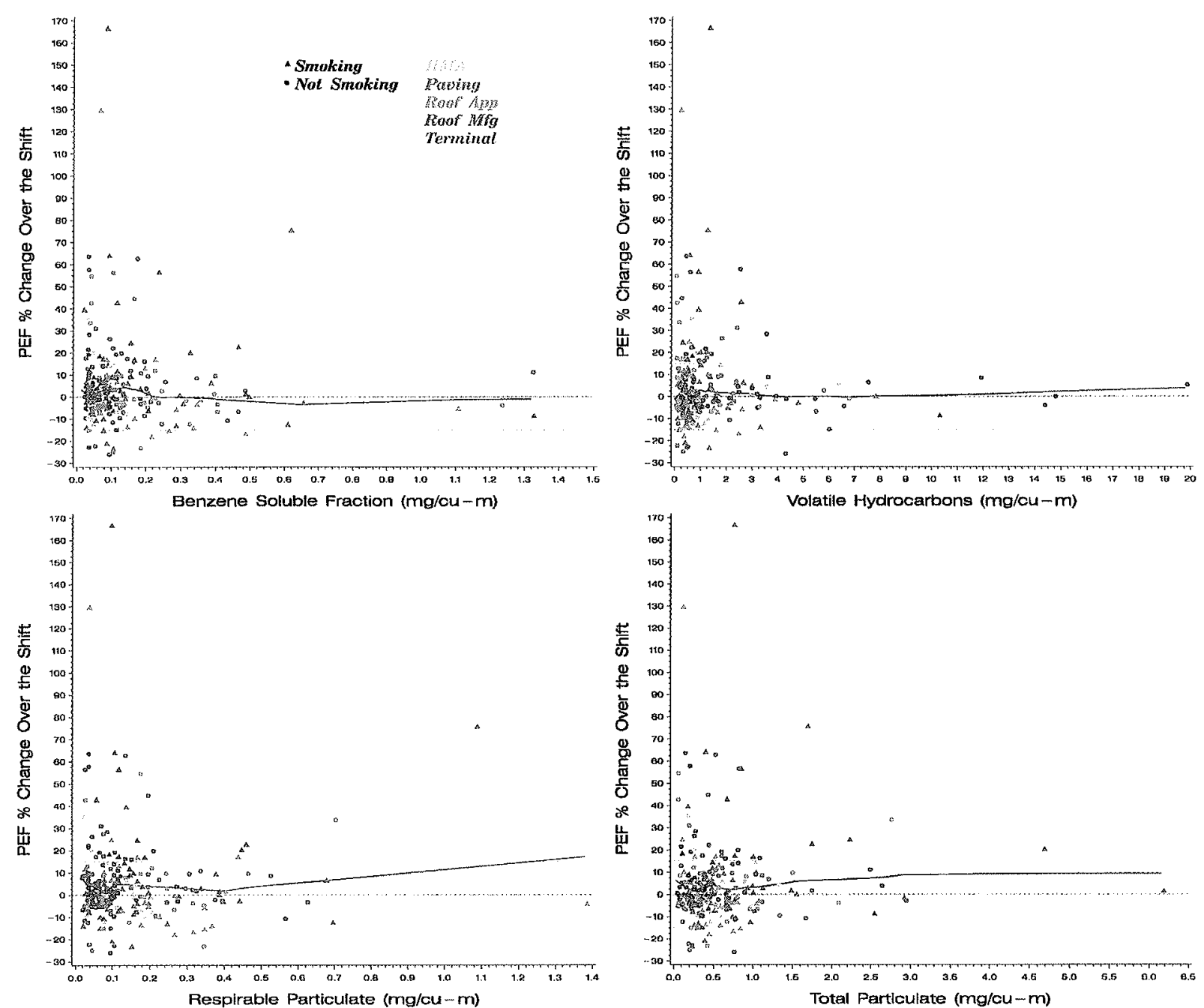

Figure 5. Univariate nonparametric regression of the percentage of change in the peak expiratory flow rate (PEF\%) versus the total particulate (TP), respirable particulate (RP), benzene soluble fraction of the TP (BSF), and volatile hydrocarbons (VHC). (See appendix 3 for an explanation of the industry segments.)

\section{Symptom sum}

Logistic regression. The sum of the symptom scores was categorized into 6 groups of roughly equal size. As a first step, 2 separate models were fit. A model which met the proportional odds assumption was fit with the demographic variables smoker, gender, site and height; the variables race, age, and weight were excluded as they were not statistically significant or caused the model to violate the proportional odds assumption. Then the exposure variables were fit in a separate model. Formaldehyde was excluded because it had unreasonable parameter estimates and did not meet the proportional odds assumption. The terms from both models were used in a newly formed third model. After dropping smoking status, nitrogen dioxide, sulfur dioxide, hydrogen sulfide, and carbon monoxide as not statistically significant, a model which met the proportional odds assumption was formed. The final model was significant at $\mathrm{P}<0.001$ by the score test. These results are summarized in table 8 (page 198). The statistically significant terms of the model were female gender, site (roofing manufacture versus hot mix asphalt), and cigarettes smoked during shift (RR $=1.06$ for each additional cigarette) .

No apparent or consistent associations were observed between the symptom sum and exposure to asphalt fumes according to the parametric statistical analyses.

\section{Individual symptoms}

Logistic regression. Each symptom score was categorized into 4 groups of roughly equal size. For the individual symptom analyses, only the 4 symptoms with incidence rates of $4 \%$ or more of the time with the symptom were studied individually with logistic regression analyses. To allow the models to converge, some variables were dropped from the model. For the nose irritation model, work location, gender, BSF, formaldehyde, hydrogen sulfide, sulfur dioxide, and nitrogen dioxide were dropped. For throat irritation, gender, RP, BSF and 

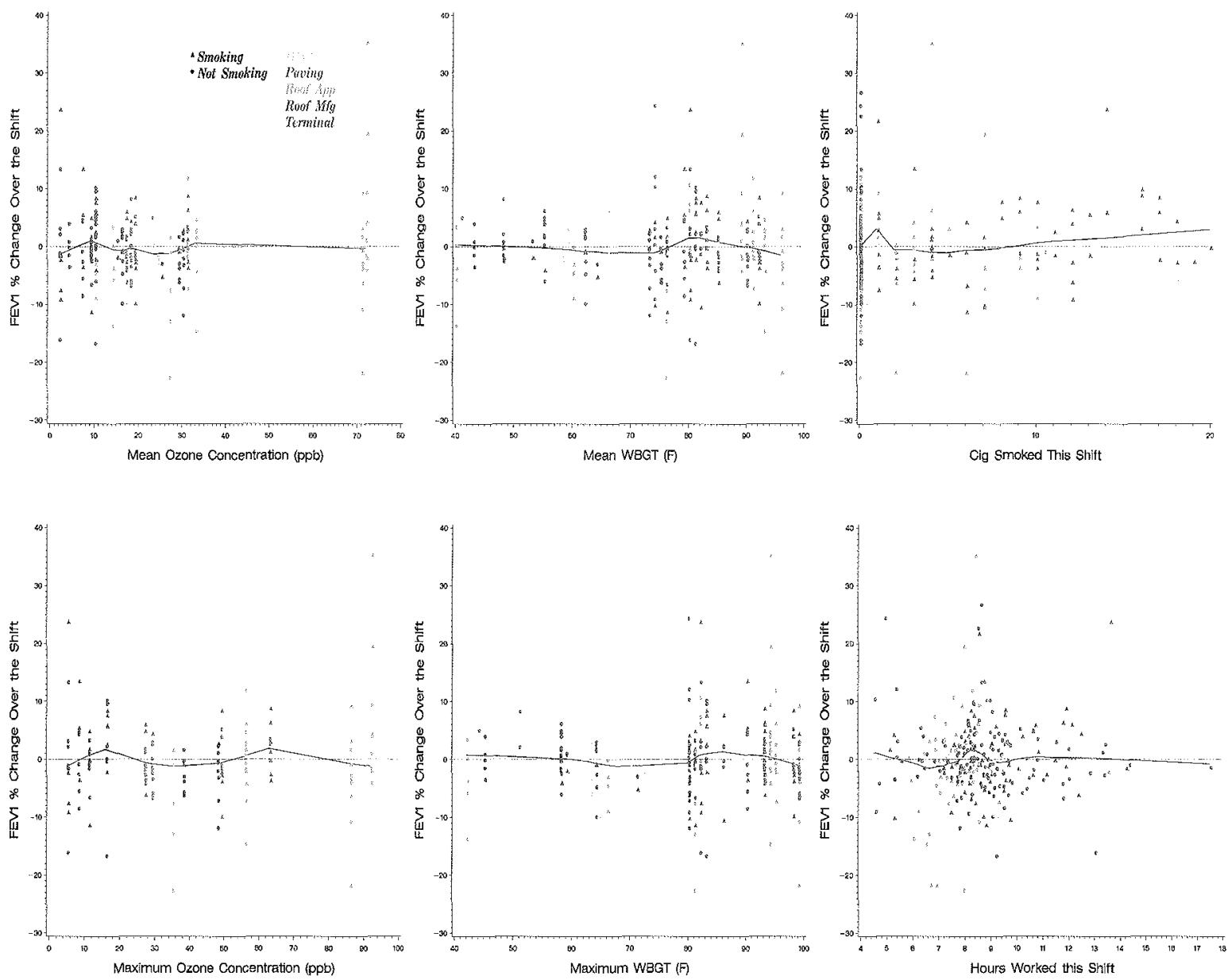

Figure 6. Univariate nonparametric regression of the percentage of change in the forced expiratory volume in 1 second versus the mean ozone concentration, maximum ozone concentration, mean wet-bulb globe temperature, maximum wet-bulb globe temperature (WBGT), cigarettes (cig) smoked, and hours worked. (See appendix 3 for an explanation of the industry segments.)

Table 8. Logistic regression results for the symptom sum scores. (OR $=$ odds ratio, $95 \% \mathrm{Cl}=95 \%$ confidence interval)

\begin{tabular}{lcccrr}
\hline Variable & $\begin{array}{c}\text { Degrees } \\
\text { of freedom }\end{array}$ & $\begin{array}{c}\text { Parameter } \\
\text { estimate }\end{array}$ & Pr>chi-square & OR & $95 \% \mathrm{Cl}$ \\
\hline Gender & 1 & 2.05 & 0.01 & 7.75 & $1.94-30.99$ \\
Pavers versus hot-mix asphalt manufacturing & 1 & 0.80 & 0.18 & 2.23 & $0.69-7.15$ \\
Roofers versus hot-mix asphalt manufacturing & 1 & 1.07 & 0.08 & 2.93 & $0.86-9.91$ \\
Roofing manufacturing versus hot-mix asphalt manufacturing & 1 & 1.68 & 0.01 & 5.36 & $1.66-17.32$ \\
Terminal versus hot-mix asphalt manufacturing & 1 & 0.74 & 0.26 & 2.09 & $0.58-7.61$ \\
Height & 1 & 0.09 & 0.08 & 1.10 & $0.99-1.22$ \\
Total particulate (mg/m $\left.\mathrm{m}^{3}\right)$ & 1 & -0.11 & 0.63 & 0.89 & $0.57-1.41$ \\
Respirable particulate collected using a cyclone sampler $\left(\mathrm{mg}^{2} / \mathrm{m}^{3}\right)$ & 1 & 1.37 & 0.12 & 3.93 & $0.70-21.96$ \\
Benzene soluble fraction of the total particulate $\left(\mathrm{mg} / \mathrm{m}^{3}\right)$ & 1 & 1.29 & 0.16 & 3.63 & $0.59-22.38$ \\
Volatile hydrocarbons collected using a charcoal tupe $\left(\mathrm{mg} / \mathrm{m}^{3}\right)$ & 1 & -0.03 & 0.61 & 0.97 & $0.85-1.10$ \\
Cigarettes & 1 & 0.06 & 0.02 & 1.06 & $1.01-1.12$ \\
Significance of score test,P & & & 0.0001 & & \\
\hline
\end{tabular}

hydrogen sulfide were dropped. For coughing, working at a terminal was combined with working in hot-mix asphalt manufacturing; gender, RP, and hydrogen sulfide were dropped. For the headache analyses, location of work, gender, hydrogen sulfide, formaldehyde and nitrogen dioxide were dropped.

Analyses of prevalence for each of the 4 symptoms were also done using only presence or absence of the symptom. These analyses provided a further test for an exposure-response relationship and required fewer 
assumptions. The $\mathrm{R}^{2}$ values were all $<0.15$ for the final models. No statistically significant associations were observed by either analysis (table 9 ).

None of these analyses indicated that any asphalt fume exposure variable was statistically significantly related to the incidence or prevalence of the symptom being tested with parametric statistical techniques.

Nonparametric regression. Plotting symptom sums versus asphalt fume exposure variables (figure 7, page 200) showed essentially a flat pattern indicating no exposureresponse relationship. The total particulate and respirable particulate plots showed a slight increase in the symptom sum at higher exposures on the basis of the influence of 2 data points in each case. However, these observations are at the extreme high end of the exposure scale, and yet the symptom sums were still low. A similar case was found for VHC, except there was only 1 point exerting the influence.

The nonparametric regression analyses indicated that none of the exposure variables for asphalt fumes were associated with the symptom sum.

\section{DISCUSSION}

This study was designed to determine whether there was an exposure-response relationship between measures of asphalt fume exposure and health outcomes. A probable work-related response was considered likely if the PFT was reduced during the shift or the incidence or severity of symptoms became greater as exposure increased. No exposure-response trends were observed, and therefore no apparent work-related adverse health outcome was apparent in association with exposure to asphalt fumes. Since there were no associations of health outcome with exposure, no adverse effect level was determined and no component of asphalt fumes could be identified as causing an effect.

There were negligible exposures to potentially confounding pollutants from nonasphalt or background sources (ie, nitrogen dioxide, sulfur dioxide, carbon monoxide), and no effect of other confounders (ozone, cigarettes, heat stress, hours worked) on changes in lung function or symptoms.

\section{Strengths and limitations of this shift study}

This study has several advantages that allow for some unambiguous conclusions. The response variables include objective (changes in lung function) and subjective (symptoms) measures of acute health outcomes and a comprehensive assessment of exposure. The changes in lung function included measures of both large and small airway obstruction. The incidence of acute,

Table 9. Logistic regression results for individual symptom scores. $(\mathrm{df}=$ degrees of freedom, $\mathrm{PE}=$ parameter estimate, $\mathrm{P}=$ pr>chi-square, $\mathrm{OR}=$ odds ratio, $\mathrm{HMA}=$ hot-mix asphalt manufacturing)

\begin{tabular}{|c|c|c|c|c|c|c|c|c|c|c|c|c|c|}
\hline \multirow[t]{2}{*}{ Variable } & \multirow[t]{2}{*}{$d \mathbf{f}$} & \multicolumn{3}{|c|}{ Nose irritation } & \multicolumn{3}{|c|}{ Throat irritation } & \multicolumn{3}{|c|}{ Coughing } & \multicolumn{3}{|c|}{ Headache } \\
\hline & & PE & $P$ & $\mathrm{OR}$ & $P E$ & $\mathrm{P}$ & $\mathrm{OR}$ & PE & $\mathrm{P}$ & $\mathrm{OR}$ & PE & $P$ & OR \\
\hline Current smoker & 1 & 1.18 & 0.09 & 3.27 & 0.67 & 0.42 & 1.95 & 0.09 & 0.89 & 1.10 & -0.44 & 0.61 & 0.65 \\
\hline Former smoker & 1 & -0.16 & 0.86 & 0.86 & -0.27 & 0.76 & 0.76 & -0.40 & 0.61 & 0.67 & 0.19 & 0.82 & 1.21 \\
\hline Black & 1 & 0.24 & 0.65 & 1.27 & 0.05 & 0.94 & 1.05 & 0.32 & 0.56 & 1.38 & -1.06 & 0.18 & 0.35 \\
\hline Hispanic & 1 & 1.23 & 0.24 & 3.41 & -1.57 & 0.25 & 0.21 & 0.26 & 0.83 & 1.30 & 0.26 & 0.84 & 1.29 \\
\hline Pavers versus HMA & 1 & - & - & - & 0.86 & 0.48 & 2.35 & - & - & - & - & - & - \\
\hline Roofers versus HMA & 1 & - & - & - & -1.55 & 0.36 & 0.21 & - & - & - & - & - & - \\
\hline Roofing manufacturing versus HMA & 1 & - & - & - & 1.55 & 0.21 & 4.70 & - & - & - & - & - & - \\
\hline Terminal versus HMA & 1 & - & - & - & 0.50 & 0.70 & 1.64 & - & - & - & - & - & - \\
\hline Age & 1 & -0.009 & 0.69 & 0.99 & -0.037 & 0.22 & 0.96 & 0.002 & 0.95 & 1.00 & -0.03 & 0.30 & 0.97 \\
\hline Height & 1 & 0.09 & 0.39 & 1.09 & -0.026 & 0.79 & 0.98 & 0.13 & 0.24 & 1.14 & 0.34 & 0.02 & 1.40 \\
\hline Weight & 1 & 0.003 & 0.70 & 1.00 & 0.02 & 0.03 & 1.02 & -0.006 & 0.46 & 0.99 & -0.01 & 0.12 & 0.99 \\
\hline Total particulate $\left(\mathrm{mg} / \mathrm{m}^{3}\right)$ & $t$ & 0.16 & 0.61 & 1.17 & 0.60 & 0.24 & 1.81 & -0.18 & 0.73 & 0.84 & 0.21 & 0.73 & 1.23 \\
\hline Respirable particulate $\left(\mathrm{mg} / \mathrm{m}^{3}\right)$ & 1 & 1.70 & 0.10 & 5.49 & - & - & - & - & - & - & 1.30 & 0.38 & 3.66 \\
\hline Benzene soluble fraction $\left(\mathrm{mg} / \mathrm{m}^{3}\right)$ & 1 & - & - & - & - & - & - & 0.24 & 0.88 & 1.28 & -0.90 & 0.60 & 0.41 \\
\hline Formaldehyde & 1 & - & - & - & -3.39 & 0.73 & 0.03 & -2.62 & 0.80 & 0.07 & - & - & - \\
\hline Volatile hydrocarbons $\left(\mathrm{mg} / \mathrm{m}^{3}\right)$ & 1 & -0.05 & 0.71 & 0.95 & -0.03 & 0.77 & 0.97 & -0.11 & 0.49 & 0.90 & 0.01 & 0.87 & 1.02 \\
\hline Nitrogen dioxide (ppm) & 1 & - & - & - & 3.79 & 0.53 & 44.11 & -1.22 & 0.70 & 0.30 & 0.91 & 0.27 & 2.49 \\
\hline Sulfur dioxide (ppm) & 1 & - & - & - & -4.22 & 0.14 & 0.02 & 1.00 & 0.48 & 2.72 & - & - & - \\
\hline Cabon monoxide (ppm) & 1 & 0.04 & 0.62 & 1.04 & 0.05 & 0.58 & 1.06 & -0.03 & 0.77 & 0.97 & 0.004 & 0.97 & 1.00 \\
\hline Cigarettes smoked & 1 & -0.03 & 0.62 & 0.97 & -0.11 & 0.30 & 0.90 & 0.03 & 0.67 & 1.03 & 0.02 & 0.79 & 1.02 \\
\hline Significance of score test, $\mathrm{P}$ & & & 0.28 & & & 0.72 & & & 0.98 & & & 0.55 & \\
\hline
\end{tabular}



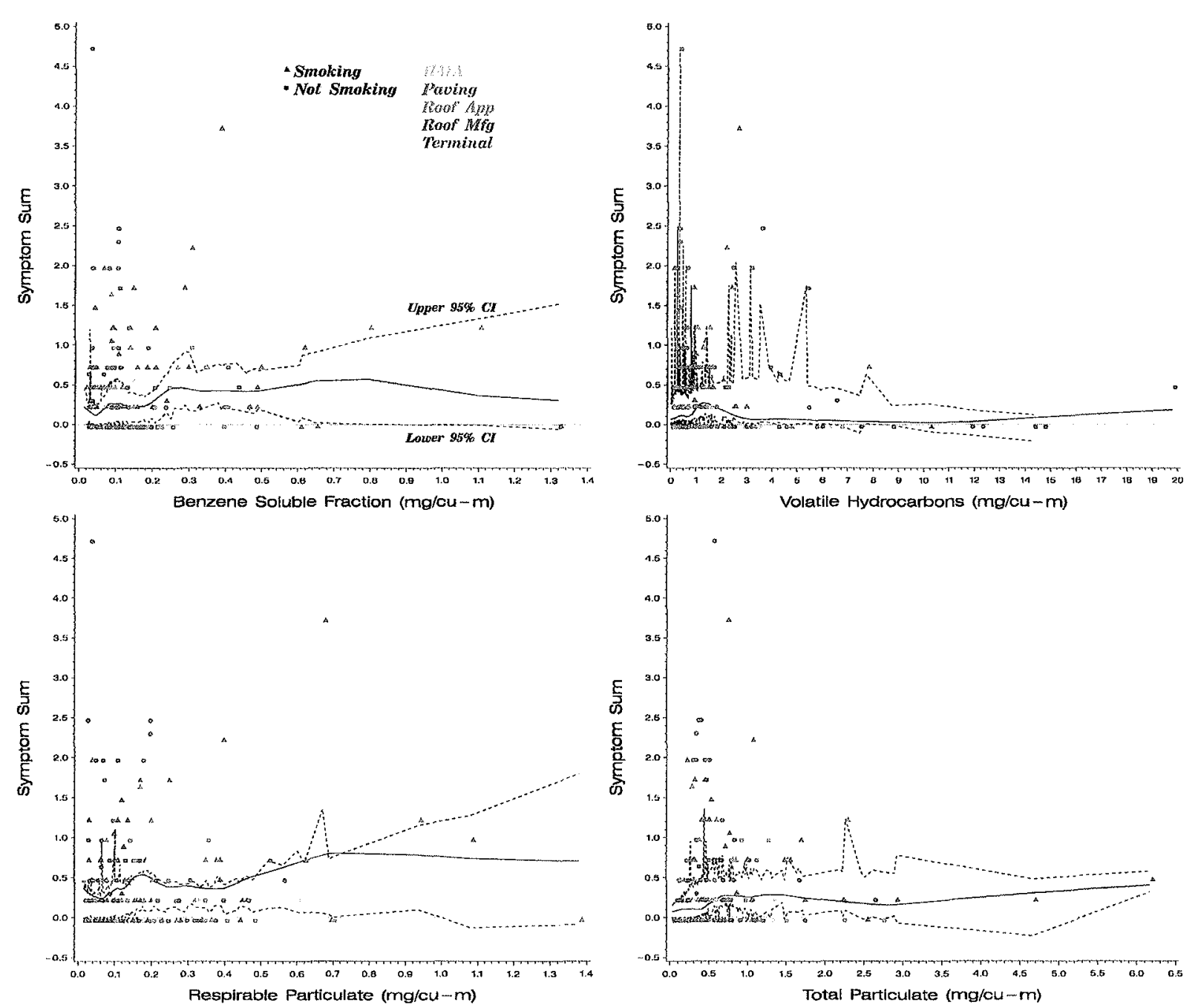

Figure 7. Univariate nonparametric regression of the symptom sum versus the total particulate (TP), respirable particulate (RP), benzene soluble fraction of the TP (BSF), and volatile hydrocarbons (VHC) with the bootstrap $95 \%$ confidence interval. (See appendix 3 for an explanation of the industry segments.)

reversible symptoms was determined at several time points over the shift so there should have been no recall bias.

Exposure was estimated from personal samples from all the participants, with due consideration to the measurement of known potentially irritating substances. Personal samples from the workers' breathing zones were obtained for all suspected irritating substances to allow adjustment for potential confounders, to determine the most sensitive and appropriate method for sampling asphalt fumes, and to determine exposure-response gradients.

This study incorporated a large number of subjects, more than is usually associated with a shift study. Despite the large sample size, the ability to estimate meaningful changes at higher concentrations was limited because of the few data points at higher concentrations. The design allowed measures of change over the shift, and this feature increased the precision of the response. The samples were drawn from the major segments of the industry under a wide variety of conditions. Volunteer bias was not a problem as there was $100 \%$ participation at every location.

A wide range of statistical techniques was utilized in the analyses, each complementing the others in the testing for associations. Where possible, the analyses were both parametric and nonparametric, and both univariate and multivariate. The data were analyzed both as continuous responses and as ordinal categories. The conclusion of no significant findings is strengthened by the visual presentation from the nonparametric analyses, as the results are transparent and not seen darkly via simplified statistical models.

This study precisely measured exposure-response relationships, and the lack of such an association was clear, unambiguous, and unaffected by any known confounders for both PFT and symptoms. Potential confounders in high enough concentrations to measure (eg, smoking, 
ozone, heat stress) were not associated with a response, and the remaining potential confounders (eg, nitrogen dioxide, sulfur dioxide, formaldahyde) were at or below the limits of detection. Since no exposure-response relationships were present, a lowest observed adverse effect level (LOAEL) could not be determined.

The lack of an exposure-response gradient may have been due to low exposures. However, the exposures in this study appear to have been comparable to the exposure assessment study of Hicks (35) and the NIOSH studies of conventional asphalt $(9-15)$ (table 10). The exposures represent the exposures of current workers in the field; efforts were made to find workers at the highest exposure levels.

The lack of an exposure-response relationship between the health outcomes and exposure variables did not allow a determination on empirical grounds as to the most appropriate sampling parameter for asphalt fumes. Neither did it allow for an estimate of the lowest observed adverse effect level. No adverse effects were apparent even up to the maximum concentrations. However, the data were sparse at higher concentrations. These findings indicate that the no adverse effect levels (NOEL) for changes in the PFT and symptoms were clearly above concentrations of $7.5 \mathrm{mg} / \mathrm{m}^{3}$ for $\mathrm{TP}, 0.6 \mathrm{mg} / \mathrm{m}^{3}$ for $\mathrm{RP}$, $0.6 \mathrm{mg} / \mathrm{m}^{3}$ for $\mathrm{BSF}$, and $8 \mathrm{mg} / \mathrm{m}^{3}$ for $\mathrm{VHC}$, for which the bulk of the data were found, and in the neighborhood (either above or below) of the maximum concentrations.

\section{Confounding variables}

A concern of this and all epidemiology studies is whether confounders have been taken into consideration. For example, a potential confounder such as smoking may have reduced the PFT and increased symptom incidence across the shift, and smoking prevalence may have also been higher among workers with higher exposure. The confounding exposure variables of potential a priori concern in this study included cigarette smoking, heat stress, exposure to ozone, and irritants from diesel exhaust (eg, nitrogen dioxide, diesel particulates, formaldehyde). The regression results showed no associations with these potential confounders. No exposure-response association with heat stress was observed in spite of several days when the WBGT was above the TLV®. The lack of an association with specific potential confounders and for all response variables strengthens the supposition that confounding did not occur.

Another indication that confounding did not occur is that the levels of respiratory irritant gases (ie, nitrogen dioxide, sulfur dioxide, formaldehyde, hydrogen sulfide) were at or near the level of detection and well below their TLV@ values. Thus these exposures were considered to be too low to produce a reduction in lung function, or produce irritating symptoms.

\section{Change in the pulmonary function tesis}

The least-squares parametric models were uninformative (small $\mathrm{R}^{2}$ ), not statistically significant as measured by a reduction in residual mean squares (F-test), and showed no statistically significant associations with any of the independent exposure variables.

The nonparametric regression curves showed no consistent tendency to drop below the no-effect line of zero change over the shift. At higher concentrations, for which there are fewer observations, the regressions became more unstable, but still showed no convincing suggestions of an adverse effect.

In summary, there were no associations between reductions in PFT and increased exposure to confounding variables, including cigarettes smoked, hours worked, heat stress, and ozone exposure, and no consistent exposure-response relationships with measures of asphalt fume exposures. Multivariate nonparametric regressions and factor analyses further support the lack of an association between across-shift reductions in lung function and any of the variables for asphalt fume exposure. These conclusions were confirmed by traditional parametric statistical techniques, as well as by less-used nonparametric techniques, supported by the actual data presented visually.

Table 10. Comparison of personal exposures to components of asphalt fumes by industry segment and job in this study, an exposure assessment study (35) and NIOSH studies of conventional asphalt paving operations $(9-15)$. ( NIOSH $=$ National Institute for Occupational Safety and Health, TP =total particulate, BSF = benzene soluble fraction)

\begin{tabular}{|c|c|c|c|c|c|}
\hline \multirow{3}{*}{$\begin{array}{l}\text { Industry segment } \\
\text { or job }\end{array}$} & \multicolumn{5}{|c|}{ Geometric means $\left(\mathrm{mg} / \mathrm{m}^{3}\right)$} \\
\hline & \multicolumn{3}{|c|}{$\mathrm{TP}$} & \multicolumn{2}{|c|}{ BSF } \\
\hline & $\begin{array}{l}\text { This } \\
\text { study }\end{array}$ & $\begin{array}{l}\text { Hicks } \\
(35)\end{array}$ & $\begin{array}{l}\mathrm{NIOSH} \\
(9-15)\end{array}$ & $\begin{array}{l}\text { This } \\
\text { study }\end{array}$ & $\begin{array}{c}\text { Hicks } \\
(35)\end{array}$ \\
\hline \multicolumn{6}{|l|}{ Paving } \\
\hline Laborer & 0.39 & 0.34 & - & 0.10 & 0.15 \\
\hline Screedman & 0.72 & 0.48 & 0.20 & 0.27 & 0.28 \\
\hline Foreman & 0.39 & 0.41 & - & 0.08 & 0.16 \\
\hline Paver operator & 0.45 & - & 0.17 & 0.11 & - \\
\hline Roller operator & 0.23 & - & 0.07 & 0.06 & - \\
\hline Traffic control & 0.16 & - & 0.14 & 0.06 & - \\
\hline \multicolumn{6}{|c|}{ Roofing manufacture } \\
\hline Coater operator & 0.69 & 1.0 & - & 0.12 & 0.2 \\
\hline Supervisor & 0.52 & 1.4 & - & 0.09 & 0.32 \\
\hline \multicolumn{6}{|l|}{ Roofing application } \\
\hline Laborer & 0.44 & 0.38 & - & 0.13 & 0.30 \\
\hline Kettleman & 0.27 & 1.0 & - & 0.15 & 0.67 \\
\hline Mop man & 0.30 & 0.51 & - & 0.16 & 0.21 \\
\hline
\end{tabular}




\section{Acute sympioms}

Overall, no consistent associations, as evaluated by both parametric (logistic) and nonparametric regression analyses, were observed between the variables for asphalt fume exposure and the incidence (symptom score and symptom sum) or prevalence of symptoms. The symptoms were mild in severity and reversible. The remaining discussion will address some of the issues related to the measurement and significance of acute symptoms.

The rates for the "dummy symptoms" (ringing in ears, difficulty swallowing) occurred less than $1 \%$ of the time (as did nose bleed and loss of appetite). Thus there is no reason to believe that the symptom rates were spuriously elevated. Because incidence was so low, only symptoms with incidences greater than $4 \%$ of the time were analyzed separately for exposure-response relationships.

Because of the frequent administration of the questionnaire, the detection of symptoms should have been both accurate and complete. The questionnaire used in this study had a format similar to that used by $\mathrm{Hu}$ et al (20) in their study of acute symptoms of eye and respiratory irritation among workers exposed to sodium borate dust. However, Hu et al (20) queried the workers every hour and identified the onset of symptoms to the nearest 15 minutes. They used a direct-reading real-time aerosol monitor to correlate symptoms with peak exposures. In this study the questionnaire was administered about every 2 hours, and the whole period was considered since the last questionnaire was considered to be either free of symptoms or symptomatic. Symptom incidence was determined during a maximum of 42 -hour intervals versus a maximum of 32 15-minute intervals for Hu et al (20). Therefore, the incidence of symptoms in the 2 studies is not totally comparable.

Eisen et al (19) hypothesized that a reduction in $\mathrm{FEV}_{1.0}$ or PEF may accompany the occurrence of the most common acute respiratory symptoms of upper airway irritation (eg, nasal irritation, cough, chest tightness, wheeze, breathlessness). However, in our study, the reduction in $\mathrm{FEV}_{1.0}, \mathrm{PEF}$, or other spirometric measures across the shift showed no consistent association with symptoms of nose, throat or eye irritation, coughing, or difficulty breathing (data not shown but available from the authors).

All the symptoms assessed in this study are acute and reversible and can be caused by short-term "peak" exposures. The induction of such symptomatic responses in some situations may occur within minutes and may last for only minutes after the "peak" exposure occurs (19). We found no increase in individual or combined symptoms associated with time-weighted average measures of exposure. The question of peak exposure could not be addressed in this study, as it was not realistic or feasible to use the direct-reading instruments required for such an analysis. The symptoms were of such mild severity that it is an open question whether they should be considered adverse, or would be remembered if assessed at the end of the shift rather than several times during the shift. Eisen et al (19) argued that acute reversible symptoms may "cause immediate discomfort and may be precursors of chronic disease". However, we know of no evidence that these symptoms are precursors of chronic disease, and the discomfort to asphalt workers in our study was of a mild nature. For example, eye irritation was at times described as due to sweat "stinging the eyes".

These results appear contrary to those of Norseth et al (7) as no exposure-response relationship was observed between symptoms and BSF. However, a direct comparison was not possible because of the variety of differences between the 2 studies. For example, our study included workers from other segments of the asphalt industry, and not just pavers. None of our analyses indicated a differential effect due to job segment, and no segment effect can be seen in the data plots. Our measure of response was the fraction of time with the symptom, and not the number of days of the week when the symptoms occurred for any fraction of the time. Our symptom questionnaire was administered 5 times per shift, instead of being self-administered once at the end of the week. Our study had precise estimates of symptom incidence and exposure-response associations because questionnaires were administered on the same day as the exposure was measured.

Exposure cannot be compared between the 2 studies because the Norwegian estimate was a weekly average while ours was a daily average. The only common exposure parameter was the solvent extractable fraction of total particulate (benzene in our study and carbon disulfide in the Norwegian study). Since it was not possible to compare exposure by job, it was not possible to compare even weekly and daily averages.

\section{Concluding remarks}

\section{Pulmonary function measures}

There were no consistent findings of statistical, biological, or practical importance from these data that relate the measured values of asphalt fume exposure to any of the 4 pulmonary function measures with the use of any of the statistical methods.

\section{Symptoms}

There were no practically significant findings from these data to relate any of the symptoms to any of the measured exposures to asphalt fumes with the use of any of the statistical methods. 


\section{Overall conclusion}

These data indicate that no association between acute reversible changes in pulmonary function or the incidence of symptoms and personal breathing zone concentrations of asphalt fumes at concentrations at which there is adequate sample sizes or at a maximum concentration at which the data are sparse:

- $1.5 \mathrm{mg} / \mathrm{m}^{3}$ total particulate, maximum $6.2 \mathrm{mg} / \mathrm{m}^{3}$

- $\approx 0.6 \mathrm{mg} / \mathrm{m}^{3}$ respirable particulate, $1.4 \mathrm{mg} / \mathrm{m}^{3}$ maximum

- $\approx 0.6 \mathrm{mg} / \mathrm{m}^{3}$ benzene-soluble fraction of total particulate, $1.3 \mathrm{mg} / \mathrm{m}^{3}$ maximum

- $\approx 8 \mathrm{mg} / \mathrm{m}^{3}$ volatile hydrocarbons, $19.8 \mathrm{mg} / \mathrm{m}^{3}$ maximum

\section{ACKNOWLEDGMENTS}

The following persons were involved in the study at various times in one or more ways: TW Armstrong, LS Bishop, SM Bowes, D Donaleski, DE Dunzik, V Fowler, RD Gilman, GA Golias, BC Haigney, G Jorgensen, PE Kaufmann, L Kupper, KL Moore, A O'Neill, K Penney, CM Phillips, LE Rudd, EA Sales, JA Suder, WE Thar, $M$ Vodarsik. We also wish to thank all the workers who participated in the study; the companies who provided access to the workers; the AIEOC members who reviewed the protocol and final report, as well as related aspects of the asphalt study; and member associations who made the study possible.

\section{REFERENCES}

1. Asphalt Institute (AI). Report to OSHA and NIOSH: Status of Asphalt Industry Steering Committee research program on the health effects of asphalt fumes and recommendation for a worker health standard. Lexington (KY): Asphalt Institute, 1990.

2. National Institute for Occupational Safety and Health (NIOSH). NIOSH working paper on occupational exposure to asphalt [draft]. Cincinnati (OH), 1996. USDHHS/PHS/NI$\mathrm{OSH}$.

3. American Conference Governmental Industrial Hygienists (ACGIH). Documentation of the threshold limit values and biological exposure indices. 6th edition. Cincinnati $(\mathrm{OH})$ : American Conference Governmental Industrial Hygienists, 1991.

4. American Conference Governmental Industrial Hygienists (ACGIH), TLVs ${ }^{\circledR}$, BEIS ${ }^{\circledR}$ : threshold limit values for chemical substances and physical agents biological exposure indices. Cincinnati (OH): ACGIH, 1996.

5. Hervin RL, Emmett EA. Sellers and Marquis Roofing Company, AJ Shirt Roofing Company, Western Roofing Company, and the Quality Roofing Company; a joint venture, Kansas City, MO, June 1976. Cincinnati (OH): National Institute for Occupational Safety and Health, 1976. Health hazard eval- uation determination report, no 75-102-304.

6. Hervin RL, Emmett EA. Health hazard evaluation/toxicity determination, Western Roofing Co, Sellers \& Marquis Roofing Co, AJ Shirk Roofing Co, Quality Roofing Co, Kansas City, MO 64130. Cincinnati (OH): National Institute for Occupational Safety and Health, 1976. Report no NIOSH-TRHHE-75-194-324, August 1976.

7. Norseth T, Waage J, Dole T. Acute effects and exposure to organic compounds in road maintenance workers exposed to asphalt. Am J Ind Med 1991;20:737-44. [Also complete reports].

8. Chase RM, Liss GM, Cole DC, Heath B. Toxic health effects including reversible macrothrombocytosis in workers exposed to asphalt fumes. Am J Ind Med 1994;15:278-89.

9. Almaguer D, Miller AK, Hanley KW. Martin Paving Company, Yeehaw Junction, FL, March 1996. Cincinnati (OH): National Institute for Occupational Safety and Health, 1996. Health hazard evaluation report HETA 95-0118-2565.

10. Miller AK, Burr G. Health hazards evaluation report: BardonTrimount, Stoughton, MA. Cincinnati (OH): US Department of Health and Human Services, Public Health Service, Centers for Disease Control \& Prevention, National Insitute for Occupational Safety \& Health, 1998. NIOSH report no HETA97-0232-2674.

11. Hanley KW, Miller AK. Spartan Paving Company, Lansing, Mich, March 1996. Cincinnati (OH): National Institute for Occupational Safety and Health, 1996. Health hazard evaluation report HETA 94-0365-2563.

12. Hanley KW, Miller AK. Granite Construction Company, Sacramento, CA, March 1996. Cincinnati (OH): National Institute for Occupational Safety and Health, 1996. Health hazard evaluation report HETA 94-0408-2564.

13. Kinnes GM, Miller AK, Burr GA. The Sim J Harris Company; San Diego, California; December 1966. Cincinnati (OH): National Institute for Occupational Safety and Health, 1996. Health hazard evaluation report HETA 96-0130-2619.

14. Miller AK, Burr GA. Koester Equipment Company; Evansville, Indiana; December 1996. Cincinnati (OH): National Institute for Occupational Safety and Health, 1996. Health hazard evaluation report HETA 95-0307-2603.

15. Miller AK, Burr GA. Staker Construction Company, Casa Grande, Arizona, October 1996. Cincinnati (OH): National Institute for Occupational Safety and Health, 1996. Health hazard evaluation report HETA 96-0072-2603.

16. Dunzik DE, Gilman RD, Haigney BC, Vincent WJ. Evaluation and enhancement of the performance of benzene solubles methods for asphalt fume assessment. Appl Occup Environ Hyg 1996;13:166-71.

17. American Thoracic Society. Standardization of spirometry, 1994 update. Am J Respir Crit Care Med 1995;152:110736.

18. Kellie SE, Attfield MD, Hankinson JL, Castellan RM. The ATS spirometry variability criteria association with morbidity and mortality in an occupational cohort of coal miners. Am J Epidemiol 1987; 125:437-44.

19. Eisen EA, Wegman DH, Kriebel D, Woskie SR, Hu X. An epidemiological approach to the study of acute reversible health effects in the workplace. Epidemiology 1991;2:26370 .

20. Hu X, Wegman DH, Eisen EA, Woskie SR, Smith RG. Doserelated irritant symptom response to occupational exposure to sodium borate dusts. Br J Ind Med 1992;49:706-13.

21. Blom G. Statistical estimates and transformed beta variables. New York (NY): J Wiley and Sons, 1958. 
22. Cleveland WS, Grosse E, Shyu WM. Local regression models: chapter 8. In: Chambers JM, Hastie TJ, editors. Statistical models. New York (NY): S Chapman and Hall, 1992.

23. Härdle W. Applied nonparametric regression. New York (NY): Cambridge University Press, 1990.

24. Efron B, Tibshirani R. An introduction to the bootstrap. New York (NY): Chapman and Hall, 1993.

25. Amercian Thoracic Society. Lung function testing: selection of reference values and interpretative strategies. Am Rev Respir Dis 1991;144:1202-18.

26. Lebowitz MD, Quackenboss J, Camilli AE, Bronnimann D, Holberg CJ, Boyer B. The epidemiology importance of intraindividual changes in objective pulmonary responses. Eur $\mathbf{J}$ Epidemiol 1987;3:390 -8 .

27. Quakenboss JJ, Lebowitz MD, Hayes C, Young CL. Respiratory responses to indoor/outdoor air pollutants: combustion pollutants, formaldehyde, and particulate matter. In: Harper JP, editor. Combustion processes and the quality of the indoor environment. Philadelphia (PA): Air and Waste Management Association (AWMA), 1989:280-93.

28. Venables KM, Burge PS, Davison AG, Taylor AJN. Peak flow rate records in surveys: reproducibility of observers reports. Thorax 1984;39:828-32.

29. Hankinson, JL. Pulmonary function testing in the screening of workers: guidelines for instrumentation, performance, and interpretation. J Occup Med 1986;28:1081-92.

30. Merchant JA, Halprin GM, Hudson AR, Kilburn KH, McKenzie WN, Bermanzohn P, et al. Evaluation before and after exposure - the pattern of physiological response to cotton dust. Ann NY Acad Sci 1974;221:38-43.

31. Lippmann $M$. Health significance of pulmonary function responses to airborne irritants, J Air Poll Control Assoc 1988; 38:881-7.

32. Balmes JR. Chapter 13: asthma. In: Harber P, Schenker MB, Balmes JR, editors. Occupational and environmental respiratory disease. St Louis (MO): Mosby Publishing Co, 1996.

33. Armstrong BG, Sloan M. Ordinal regression models for epidemiologic data. Am J Epidemiol 1989:129:191-204.

34. McCullagh P, Nelder JA. Generalized linear models. 2nd ed. New York (NY): Chapman \& Hall, 1989.

35. Hicks J. Asphalt industry cross-sectional exposure assess ment study. Appl Occup Environ Hyg 1995;10:840—8.

\section{APPENDIXI}

\section{Summary of exposure and response variables measured in a shift study of asphalt workers}

\section{Exposures}

Breathing zone, source, and background

Total particulate (TP)

Respirable particulate (RP)

Benzene soluble fraction of TP (BSF)

Volatile hydrocarbons (VHC)

Nitrogen dioxide $\left(\mathrm{NO}_{2}\right)$

Sulfur dioxide $\left(\mathrm{SO}_{2}\right)$

Hydrogen sulfide $\left(\mathrm{H}_{2} \mathrm{~S}\right)$

Carbon monoxide (CO)

Formaldehyde (HCHO)

Other

Ozone (area)

Cigarettes smoked ( 2-hour intervals)

Wet bulb globe temperature (WBGT) (area, 2-hour intervals)

Amines (source)

Particle size distribution (source)

\section{Responses}

Changes in lung function ( $\triangle P F T)$

Forced expiratory volume in $1 \mathrm{~s}(\mathrm{l})\left(\mathrm{FEV}_{1.0}\right)$

Forced vital capacity (liters) (FVC)

Peak expiratory flow rate $(1 / \mathrm{s})(\mathrm{PEF})$ (before and after shift and at 2-hour intervals)

Average forced expiratory flow rate between 25\% and $75 \%$ of forced vital capacity $(\mathrm{l} / \mathrm{s})\left(\mathrm{FEF}_{25-75}\right)$

Symptoms (before and after shift and at $\sim 2$-hour in tervals) (severity scale $=$ no to severe)

Eyes irritated

Nose irritated

Sneezing bout

Nose bleed

Throat irritated

Coughing

Difficulty breathing

Headache

Dizzy

Nausea

Itching skin

Ringing in ears

Abnormally tired

Reduced appetite

Difficulty swallowing 


\section{APPENDIX II}

\section{Abbreviations and terms used in this report}

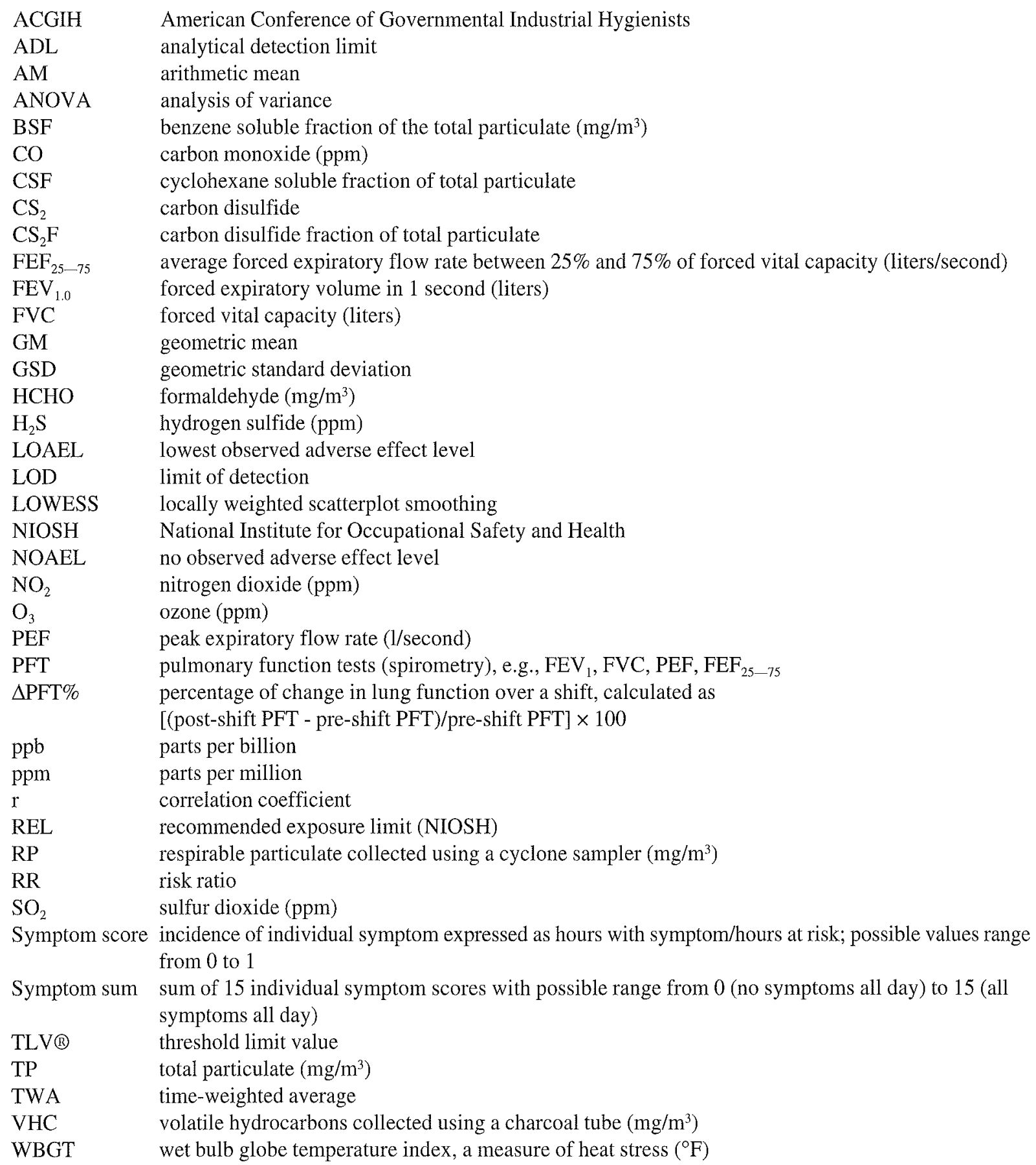




\section{APPENDIX III}

Summary of exposure measurements by industry segments and job

\begin{tabular}{|c|c|c|c|c|c|c|c|c|c|}
\hline \multirow[t]{2}{*}{ Industry segment } & \multirow[t]{2}{*}{$N$} & \multicolumn{2}{|c|}{$\begin{array}{c}\text { Total particulate } \\
\left(\mathrm{mg} / \mathrm{m}^{3}\right)\end{array}$} & \multicolumn{2}{|c|}{$\begin{array}{l}\text { Respirable particulate } \\
\qquad\left(\mathrm{mg} / \mathrm{m}^{3}\right)\end{array}$} & \multicolumn{2}{|c|}{$\begin{array}{l}\text { Benzene-soluble } \\
\text { fraction }\left(\mathrm{mg} / \mathrm{m}^{3}\right)\end{array}$} & \multicolumn{2}{|c|}{$\begin{array}{l}\text { Volatile hydrocarbons } \\
\qquad\left(\mathrm{mg} / \mathrm{m}^{3}\right)\end{array}$} \\
\hline & & GM & Maximum & GM & Maximum & GM & Maximum & GM & Maximum \\
\hline \multicolumn{10}{|c|}{ Hot mix asphalt manufacturing: personal exposures by job } \\
\hline Laborer & 6 & 0.34 & 0.99 & 0.04 & 0.08 & 0.04 & 0.09 & 1.05 & 2.03 \\
\hline Loader operator & 5 & 0.70 & 1.30 & 0.12 & 0.15 & 0.05 & 0.09 & 0.89 & 6.28 \\
\hline Mechanic & 2 & 0.86 & 1.31 & 0.44 & 0.60 & 0.05 & 0.10 & 1.37 & 1.49 \\
\hline Plant operator & 3 & 0.22 & 0.29 & 0.08 & 0.20 & 0.07 & 0.09 & 1.50 & 2.82 \\
\hline Supervisor or clerk & 4 & 0.48 & 0.56 & 0.17 & 0.20 & 0.09 & 0.14 & 0.89 & 1.21 \\
\hline \multicolumn{10}{|c|}{ Asphalt distribution terminals: personal exposures by job } \\
\hline Emulsion cutback & 4 & 0.33 & 0.44 & 0.06 & 0.06 & 0.06 & 0.10 & 4.72 & 7.46 \\
\hline Laboratory technician & 7 & 0.23 & 0.64 & 0.07 & 0.12 & 0.05 & 0.11 & 10.6 & 19.80 \\
\hline Loader & 14 & 0.20 & 0.58 & 0.06 & 0.11 & 0.04 & 0.11 & 0.75 & 3.11 \\
\hline Manager & 4 & 0.26 & 0.77 & 0.09 & 0.16 & 0.05 & 0.09 & 1.19 & 2.42 \\
\hline Mechanic & 2 & 0.17 & 0.20 & 0.09 & 0.10 & 0.05 & 0.10 & 2.60 & 3.23 \\
\hline Miscellaneous & 10 & 0.19 & 2.51 & 0.06 & 0.15 & 0.09 & 1.32 & 1.67 & 10.20 \\
\hline Office & 6 & 0.08 & 0.29 & 0.04 & 0.09 & 0.04 & 0.08 & 0.45 & 0.75 \\
\hline \multicolumn{10}{|c|}{ Roofing manufacturing: personal exposures by job } \\
\hline Coater operator & 17 & 0.69 & 2.46 & 0.13 & 0.33 & 0.12 & 1.32 & 0.84 & 1.43 \\
\hline Dry end operator & 31 & 0.64 & 6.16 & 0.07 & 0.56 & 0.09 & 0.48 & 0.75 & 4.22 \\
\hline Granule operator & 4 & 2.18 & 2.92 & 0.32 & 0.45 & 0.21 & 0.46 & 0.60 & 0.61 \\
\hline Miscellaneous & 4 & 0.24 & 0.47 & 0.05 & 0.06 & 0.03 & 0.03 & 0.88 & 3.14 \\
\hline Stillman & 2 & 0.22 & 0.34 & 0.05 & 0.06 & 0.05 & 0.10 & 6.28 & 8.73 \\
\hline Supervisor & 3 & 0.52 & 0.68 & 0.11 & 0.12 & 0.09 & 0.10 & 0.86 & 0.87 \\
\hline Warehouse & 16 & 0.50 & 2.89 & 0.06 & 0.16 & 0.04 & 0.17 & 0.30 & 0.69 \\
\hline \multicolumn{10}{|c|}{ Roofing application: personal exposures by job } \\
\hline Foreman & 6 & 0.22 & 0.77 & 0.10 & 0.34 & 0.12 & 0.34 & 0.34 & 3.21 \\
\hline Kettleman & 4 & 0.27 & 0.72 & 0.23 & 0.34 & 0.15 & 0.48 & 0.15 & 2.39 \\
\hline "Laborer, miscellaneous" & 7 & 0.17 & 0.35 & 0.06 & 0.17 & 0.06 & 0.22 & 0.44 & 6.71 \\
\hline Mop man & 8 & 0.30 & 0.54 & 0.16 & 0.40 & 0.16 & 0.39 & 0.41 & 1.19 \\
\hline Roof laborer & 37 & 0.44 & 2.73 & 0.16 & 1.38 & 0.13 & 1.23 & 0.28 & 3.79 \\
\hline \multicolumn{10}{|c|}{ Asphalt paving: personal exposures by job } \\
\hline Foreman & 6 & 0.39 & 1.09 & 0.13 & 0.52 & 0.08 & 0.34 & 0.44 & 1.34 \\
\hline Inspector & 7 & 0.26 & 0.47 & 0.09 & 0.17 & 0.06 & 0.13 & 0.22 & 1.61 \\
\hline Laborer & 20 & 0.39 & 1.52 & 0.15 & 0.39 & 0.10 & 0.49 & 0.73 & 7.72 \\
\hline Paver operator & 7 & 0.45 & 0.71 & 0.21 & 0.67 & 0.11 & 0.38 & 0.77 & 2.56 \\
\hline Roller operator & 13 & 0.23 & 0.64 & 0.05 & 0.24 & 0.06 & 0.28 & 0.17 & 3.22 \\
\hline Screed operator & 12 & 0.72 & 1.66 & 0.27 & 1.08 & 0.27 & 0.65 & 1.45 & 5.72 \\
\hline Taper & 1 & & 0.70 & & 0.19 & & 0.07 & & 0.41 \\
\hline Traffic control & 13 & 0.16 & 0.71 & 0.03 & 0.06 & 0.06 & 0.24 & 0.09 & 0.41 \\
\hline Truck driver & 2 & 0.21 & 0.34 & 0.05 & 0.08 & 0.06 & 0.09 & 0.28 & 0.33 \\
\hline
\end{tabular}

Bold face indicates highest values in that segment of the industry.

GM =geometric eman.

Received for publication: 7 September 1998 